Gerión. Revista de Historia Antigua

ISSN: 0213-0181

http://dx.doi.org/10.5209/geri.71945

\title{
La grande casquería lusitana. Nuevos y olvidados epígrafes de Augustobriga
}

\author{
Joaquín L. Gómez-Pantoja † ${ }^{1}$; Antonio González Cordero²
}

Recibido: 10 de noviembre de 2019 / Aceptado: 21 de julio de 2020

Resumen. Este trabajo, además del homenaje a la bonhomía y la erudición de Pepo Madruga, describe y analiza una docena de epígrafes procedentes de Augustobriga Vettonum, modernamente conocido como Talavera la Vieja y que desapareció bajo las aguas del río Tajo tras el cierre del pantano de Valdecañas. En contra de lo que podría pensarse, esta circunstancia ha permitido el hallazgo de nuevas inscripciones y la localización de otras que se daban por perdidas.

Palabras clave: epigrafía; Hispania; transmisión manuscrita.

\section{[en] Tasty Lusitanian Leftovers. New and Forgotten Inscriptions from Augustobriga}

Abstract. This paper, written as a homage to J.-V. Madruga, lists a dozen inscriptions from Augustobriga Vettonum, known later as Talavera la Vieja, in the province of Cáceres, and flooded by the river Tagus after completion of the Valdecañas dam half a century ago. Counter-intuitively, that same flooding has brought the finding of new inscriptions and rediscovering others that were regarded as having been lost. Keywords: Latin epigraphy; Roman Spain; Manuscripts.

Sumario. 1. Introducción. 2. Augustobriga Vettonum (Talavera la Vieja, Talaverilla). 3. Catálogo de cascotes. 3.1. Los dos olvidados del Maestro Gómez de Castro. 3.2. Entre verdades y mentiras. 3.3. Las perdidas de Hermosilla. 3.4. A lacu resurgentes. 3.5. Las ruinas de La Poveda. 4. A modo de conclusión. 5. Referencias bibliográficas.

Cómo citar: Gómez-Pantoja, J. L.; González Cordero, A. (2020): La grande casquería lusitana. Nuevos y olvidados epígrafes de Augustobriga, en Gerión 38/2, 489-517.

$1 \quad$ Universidad de Alcalá.

E-mail: gomez.pantoja@uah.es

ORCID: 0000-0002-3417-4362

2 Fundación Antonio Concha

E-mail: anmais.gc@gmail.com

ORCID: 0000-0003-2546-6248 


\section{Introducción}

En el uso actual del español, "casco" es sinónimo de caparazón, sea éste natural, como sucede con el cráneo, o el artilugio que protege al anterior y su contenido. Las vaguerías de la lengua han hecho que el término se emplee ahora para significar justamente lo contrario que indica su etimología, pues es palmaria su derivación del verbo "cascar", a su vez procedente del latín quassicare y ambos con el significado de "romper, quebrar, quebrantar". Afortunadamente todavía quedan casticismos que se atienen al sentido primigenio y el término aún designa cualquier objeto duro que se ha roto con violencia y sin contemplaciones; de ahí que se hable de cascos de metralla y vidrio, mientras que los de cerámica y piedra se conocen más como cascotes. Y está también la casquería, que nombra tanto los quebrantos, vísceras y otras grosuras del ganado de abasto como los lugares donde éstos se mercadean. En todos los casos, se trata de materiales de poca calidad y de desecho, pero que aún pueden usarse con un mínimo beneficio. Justamente lo que sucede con las inscripciones antiguas, que frecuentemente se arrancaron de sus emplazamientos originales, se rompieron para emplearlas en otros menesteres y que, al ser finalmente despreciadas, se abandonaron en desolados y escombreras. Todas las piezas de este catálogo pertenecen ciertamente a esa categoría porque provienen del abandono de dos florecientes poblaciones, que compartieron emplazamiento, aún estando separadas en el tiempo por más de un milenio.

También merecen explicación los motivos de este trabajo. Tras haberlo hecho juntos en varias ocasiones, quienes firman este artículo acordaron colaborar de nuevo cuando J. V. Madruga les presentó en 2012 una lista de inscripciones halladas en las tierras ribereñas del tramo cacereño del Tajo inmediatas al límite provincial con Toledo. El interés de la comarca radica en las afamadas (pero mal conocidas) ruinas de Augustobriga Vettonum, que uno de nosotros ha prospectado sistemáticamente desde comienzos de los años 90 del pasado siglo, tanto en el interior del vaso del embalse de Valdecañas cuando lo permitía el nivel del agua, como a pie seco por los alrededores de éste. Esas exploraciones han resultado en múltiples hallazgos de todo tipo, algunos sensacionales, y que han sido publicados con la debida diligencia. ${ }^{3} \mathrm{Al}$ confrontar los epígrafes descubiertos y fotografiados con los ya publicados, Madruga fue agrupándolos en dos categorías: los estrictamente inéditos y los que merecían revisión porque lo que ahora se lee difiere de lo transmitido por los testimonios de siglos pasados, a pesar de que las lápidas seguramente estaban entonces en mejor condición que la actual.

Desgraciadamente, las circunstancias impidieron ir más allá del propósito acordado porque nuestro colega falleció repentinamente en los primeros días de noviembre de 2013, justo cuando uno de nosotros se encontraba en el peor momento de una grave enfermedad, que exigió un complejo tratamiento y que le ha mantenido desde entonces sujeto a estricta supervisión médica. Estas circunstancias, más el progreso de un ambicioso proyecto de catalogación de las inscripciones de la provincia de Cáceres (en el que Madruga, hasta su muerte, colaboró discretamente), llevó a los autores a posponer el proyecto, a la espera de tiempos mejores y de la aparición del volumen dedicado a Augustobriga en el catálogo mencionado, lo que 
sucedió en abril de 2019. ${ }^{4}$ A la postre, la demora no ha sido perjudicial para nuestros propósitos pues solo se ha omitido una inscripción de la lista preparada hace ocho años, que ha sido sustituida por otra inédita encontrada en ese periodo.

\section{Augustobriga Vettonum (Talavera la Vieja, Talaverilla)}

Ya se ha dicho que el trabajo se ciñe a Augustobriga y a sus inmediatos alrededores, en buena parte sumergidos por las aguas embalsadas del Tajo. ${ }^{5}$ Es bien sabido que Plinio mencionó a fines del siglo I d.C. una civitas stipendiaria de ese nombre entre las dependientes del conventus Emeritensis, que más tarde se repite asignada por Ptolomeo a los vetones y que también sirvió de mansio itineris Emerita Augusta ad Caesar Augustam. ${ }^{6}$ La ciudad se construyó al borde del escarpe a cuyos pies fluía el río y dominando uno de los pocos tramos del curso medio en los que el Tajo no va encañonado: la orilla septentrional es tan plana y anchurosa que incluso permitió la formación de meandros; una situación excepcional que, después de Talavera la Vieja y hasta llegar a la plataforma litoral portuguesa, solo vuelve a repetirse en Albalat, junto a Romangordo, y en Alconétar. Augustobriga, pues, comandaba uno de los pocos lugares donde el Tajo podía cruzarse vadeando el río frente a la propia ciudad o a pie seco por el puente situado a corta distancia aguas arriba, amén de estar rodeadas por tierras con potencial agrícola y ganadero. ${ }^{7}$

A pesar de estos datos, a fines del s. XV, cuando se repobló el lugar como Talavera la Vieja, el nombre de su antecesora se había perdido por completo y solo quedaban unos impresionantes vestigios que no dejaron de atraer a curiosi que discutían sobre a qué antigua ciudad hispano-romana habían pertenecido; Ercavica, Obila y Ebora fueron las candidatas más mencionadas hasta finales el s. XIX, cuando el hallazgo en la propia Talaverilla de un epígrafe mencionando al Senatus populusque Augustobrigensium zanjó definitivamente la cuestión. ${ }^{8}$ Unos años después, J. R. Mélida reconoció el sitio con motivo de la redacción del volumen cacereño del Catálogo Monumental de España y abogó por la inclusión en la lista de los Monumentos Nacionales de dos edificios romanos aún en pie, la planta y la columnata porticada del edificio conocido popularmente como "los Mármoles" y el frente de otra construcción porticada que llamaban, también popularmente, "la Cilla". 9

$4 \quad$ Esteban Ortega 2019.

5 El territorium augustobrigense debió de ser considerablemente extenso, aunque el único dato seguro es que limitaba por el norte con los Avilenses, como prueba el mojón de la terminatio del 5-6 d.C., Gómez-Pantoja 2011 (=HEPOL 25098, con foto; Esteban Ortega 2019, 75-76, $\mathrm{n}^{\circ}$ 1405, reproduciendo erróneamente la lectura del ed. princeps).

6 Plin. NH 4.118, entre las civitates stipendiariae de la Lusitania, pero cf. CIL II 5346, que menciona el senatus populusque Augustobrigensis; Ptol. 2.5.7; It. Ant. 438.6 y Rav. 312.12.

7 El Tajo supone tal barrera para las comunicaciones que se cuentan con los dedos de la mano las poblaciones establecidas en sus orillas. Aún hoy, los cruces construidos recientemente al servicio de las grandes infraestructuras -autopistas, AVE- han requerido soluciones excepcionales. Sobre los puentes pre-modernos sobre el Tajo, vid. Machimbarrena Gogorza 1926.

$8 \quad$ CIL II 5346 (=HEpOL 4412 con foto; Esteban Ortega 2019, 32-33, nº 1352).

9 Mélida y Alinari 1919. Un documentado análisis de la historiografía sobre Augustobriga, en Morán Sánchez 1996; disponible en https://dialnet.unirioja.es/servlet/articulo?codigo=2540307 [consultado el 12 de agosto de 2019]. 
En la década de los 40 del pasado siglo, volvió a despertar el interés por Talavera la Vieja y sus ruinas, pero no tanto por razones arqueológicas cuanto económicas. Las tierras de la comarca estaban sometidas a censo enfitéutico y los agricultores que las cultivaban llevaban tiempo reclamando su redención, que solo podía hacerse de forma colectiva. Esto se consiguió en 1945, al amparo de las leyes de colonización agraria de la época, que permitieron adquirir la tierra a su propietario tradicional y luego, poner en regadío 800 ha, lo que supuso tal incremento demográfico y de riqueza que, en poco tiempo, Talavera ganó fama de ser la población con la más alta renta per capita de la provincia. La prosperidad favoreció la renovación urbana y un naciente interés por el patrimonio histórico y monumental, además de la oportunidad para los políticos locales de medir su influencia con las autoridades superiores. En 1949, el Ayuntamiento reclamó con éxito la intervención estatal para restaurar los dos Monumentos Nacionales, que amenazaban derrumbes por estar al borde del acantilado sobre el río; y dos o tres años después, se volvió a solicitar -y conseguir- que tres bustos romanos encontrados durante una de las muchas obras municipales realizadas en aquellos años no se trasladasen al Museo provincial, sino que quedasen depositados en la Casa consistorial, a la espera de la construcción de un museo monográfico. ${ }^{10}$

Simultáneamente, otros intereses estratégicos y económicos de mayor calado se entrelazaron con la Arqueología al decidirse, a comienzos de los años cincuenta del pasado siglo, la ejecución del plan de aprovechamiento integral del tramo inferior del río Tajo, entre Puente del Arzobispo, en Toledo, y el río Erjas, en la raya hispano-lusa. El objetivo era el uso de la corriente fluvial para terminar con dos problemas de la época: aumentar la superficie agrícola regable, como medio para resolver la multisecular cuestión agraria, y garantizar el abastecimiento de agua y electricidad a Madrid, que estaba experimentando un inesperado incremento de su población. En 1956, Hidroeléctrica Española se convirtió en la concesionaria de la explotación de río Tajo durante su tránsito por España, concesión que se amplió en 1968 al tramo internacional, tras la firma del Convenio de ríos fronterizos con Portugal. Entre 1957 y 1982 se construyeron en la parte española ocho saltos, dedicados fundamentalmente a la producción eléctrica, a los que hay que añadir indirectamente la refrigeración de dos reactores nucleares empleados en el mismo menester. Los regadíos, en cambio, se ejecutaron con más parsimonia $\mathrm{y}$, en ocasiones, cuando ya no eran necesarios.

En 1957 Hidrola presentó un nuevo proyecto de actuación en el tramo A del Tajo, que difería considerablemente de los propuestos desde 1900; en el último de ellos, de 1945, se habían previsto dos presas, una en el lugar que ocupa la actual de Valdecañas y otra aguas arriba de Talavera la Vieja, lo que respetaba la vega fluvial y la zona de regadío de Talavera la Vieja. En el proyecto finalmente aprobado, los avances tecnológicos en el uso del hormigón forjado y la disponibilidad de maquinaria pesada permitían construir una sola barrera, de mayor altura y diseño innovador, que

10 Los expedientes administrativos de estas y otras actuaciones se pueden consultar en el Archivo General de la Administración de Alcalá de Henares, bajo el epígrafe (03) 109.2 Caja 241 12/25 707-26.207. Primera noticia de los bustos en Jiménez de Gregorio 1955. En 1963, cuando se desalojó el pueblo, uno de los funcionarios municipales se apoderó irregularmente de los bustos, que no se recuperaron hasta 2014; actualmente se conservan en el Museo de Cáceres, junto a la placa con la mención del SPq Augustobrigenses, adquiridos en parecidas circunstancias. 
aumentaba considerablemente el volumen del agua embalsada. ${ }^{11}$ La contrapartida fue la inundación de terrenos agrícolas de gran valor y el abandono de Talavera la Vieja, lo que supuso un serio problema humano, económico y patrimonial. El último, sin duda, era el de menor entidad de los tres, pero no dejaba de constituir una paradoja jurídica: el Estado aprobó primero y luego sancionó, la destrucción de dos monumentos en cuya preservación se había obligado legalmente. ${ }^{12}$ El paliativo ofrecido fue la realización de excavaciones arqueológicas en el recinto murado de Augustobriga, con especial énfasis en el entorno de los dos Monumentos Nacionales; y la obligada imposición a la empresa concesionaria de trasladar ambos edificios a un emplazamiento seguro. La parte arqueológica se encargó a García y Bellido en 1956, con fondos del recién establecido Servicio Nacional de Excavaciones; de sus resultados solo existe un brevísimo informe de tres páginas -que trata más de los propósitos que de lo ejecutado-, aparecido pocos meses antes de que se cerrasen las compuertas del pantano. Dos publicaciones recientes añaden documentos inéditos procedentes de los archivos de García y Bellido, pero tratan más de las notas preparatorias que de sus excavaciones arqueológicas, que se ejecutaron en los años 1958 y $1959 .{ }^{13}$ A estos testimonios debe añadirse el levantamiento fotogramétrico de los dos edificios romanos, financiado y ejecutado por el Instituto Arqueológico Alemán, y cuyas fotografías y planos se custodian en el archivo de la sede madrileña de esa institución.

Un aspecto destacable de la exploración es que no incluyó los restos antiguos existentes fuera del núcleo urbano del oppidum, a pesar de que tanto los antiquiores como los últimos vecinos de Talavera la Vieja eran sabedores de ellos. Y los hay de época romana y de épocas anteriores, como sucede con el espectacular dolmen de Guadalperal, descubierto y excavado por Obermaier entre 1925 y 1927, que sigue saliendo a la superficie cuando bajan las aguas; pero también había noticias de un acueducto; de los puentes del Conde y del Buho, a los que se les atribuye origen romano; de instalaciones hidráulicas, algunas balnearias y termales, pero también con finalidad industrial; y por supuesto, varias necrópolis. Lo que no se hizo entonces, cuando hubo ocasión y posiblemente medios, lo hacen las periódicas variaciones del nivel del embalse y basta contrastar lo escrito por García y Bellido con el informe sobre la situación arqueológica a comienzos de este siglo para comprobar lo mucho que se ha descubierto después del cierre del embalse. ${ }^{14} \mathrm{El}$ proceso ha sido especialmente

11 Muchos de los avances en ingeniería y en el uso del hormigón eran frutos de la investigación nacional, como muestra Camprubí 2014.

12 Cuando aún no se había aprobado el proyecto de Valdecañas, la Comisaría General de Excavaciones Arqueológicas elevó consulta a la Dirección General de Bellas Artes sobre "cuál es la extensión de la declaración de Monumento Nacional de las ruinas romanas de Talavera, si son edificios concretos o todos ellos, dado que el Catálogo nacional no es suficientemente expresivo a estos efectos"; el organismo superior respondió "que en el Catálogo Monumental de España figuran como declaradas Monumentos histórico-Artísticos todas y cada una de la ruinas de Talavera la Vieja" (AGA, exp. cit. supra, de 8 de marzo de 1955). Sobre la historia y actividad de la mencionada Comisaría, que en 1956 cambió de nombre y estructura, Díaz Andreu - Ramírez Sánchez 2001.

13 El informe en cuestión es García y Bellido 1956-1961, que debe complementarse con la documentación inédita estudiada por Morán Sánchez 2017 y Gimeno Pascual 2016. A pesar de que los trabajos de García y Bellido fueron financiados con dinero público, el libro de actas de las reuniones del Servicio Nacional de Excavaciones (el sucesor de la extinta Comisaría), que puede consultarse en el AGA, no contiene referencia alguna a las excavaciones de Talavera la Vieja, a los resultados de la misma y a los libramientos económicos y su justificación.

14 González Cordero - Morán Sánchez 2006. 
generoso en lo referente a la epigrafía, porque la acción del agua ha puesto al descubierto lápidas inscritas que fueron expoliadas para construir las casas de Talavera la Vieja y que antes no eran visibles porque sus vecinos ocultaban cuidadosamente los indicios de antigüedad. Durante su visita, Hermosilla señala que "supe por cosa notoria, que cuando se hace ó se repara alguna casa, cuidan mucho los dueños de que el portugués (son precisamente de esta nacion los albañiles de toda aquella comarca) ponga las letras de las piedras dentro del muro de modo que no se vean, porque son (así se explican) rétulos de condenados". Cabe, sin embargo, que la real motivación fuera una ordenanza municipal de 1578 que, refrendando otra más antigua "la qual hablaba en razon de la conservacion de los edificios antiguos que hay en la dicha villa", no se permitía a vecinos y forasteros ni "romper ni desbaratar ningún edificio de los antiguos que estuvieran morados sobre la tierra, so pena se seiscientos maravedís". ${ }^{15}$

\section{Catálogo de cascotes}

\subsection{Los dos olvidados del Maestro Gómez de Castro}

A comienzos de noviembre de 1572, regresando a Toledo tras visitar en Jaraicejo al obispo de Plasencia, Alvar Gómez de Castro decidió desviarse del camino ordinario en Almaraz "y tome otro por la parte alta de la montaña con deseo de ver a Talavera la vieja". Del viaje queda el relato que el propio visitante envió por carta a Antonio Gracián, lo que le otorga la primacía de ser el más antiguo testimonio escrito sobre las ruinas locales, de las que le interesaban especialmente las del vecino castillo de los Alijares, por considerar que se trataba de la famosa Rocafrida del Romancero. Aún así, el ilustre humanista reconoció que no era el primer curioso que visitaba Talaverilla porque sus habitantes "de la Antiguallas de aquel lugar, diéronme buena razón, parescía que estaban instructos de otros que hian venido en la misma demanda". ${ }^{16}$

\section{a) Epitafio de una madre a su hija}

Gómez de Castro continua el párrafo señalando que, "y ansi me llevaron à una Hermita, ${ }^{17}$ donde estaba una Piedra de Marmol, escritas con Letras Romanas, es un

15 Hermosilla y de Sandoval y Rojas 1796, 350 y 361, respectivamente. El último secretario del Ayuntamiento de Talavera la Vieja, don Julio Brasero Arroyo, ya fallecido, mostró hace unos años a González Cordero el Libro de Ordenanzas del municipio del que Hermosilla copió literalmente la última ordenanza, que es seguramente uno de los primeros testimonios hispanos de una política de defensa del patrimonio cultural.

16 Gómez de Castro 1572, f. 98r. Obviamente se ha respetado la ortografía de éste y los restantes documentos que se citan literalmente. Una copia manuscrita de la carta de Gómez de Castro está disponible en la Biblioteca Digital Hispánica de la BNE: http://bdh-rd.bne.es/viewer.vm?id=0000087396\&page=1 [consultado el 25 de octubre de 2019]; pero resulta más cómoda la consulta de la transcripción no paginada de Sánchez Cantón 1927. Véanse también las observaciones de Sánchez Medina 2004 sobre Gómez de Castro como epigrafista.

17 La ermita es la de los Santos Mártires, que se encontraba al este del pueblo y a la vera del camino que conducía hacia el puente del Conde, Berrocalejo y la barca, es decir, la ruta entre Emérita y Toledo, lo que justifica los abundantes vestigios de su función sepulcral, algunos de ellos pertenecientes a monumentos de porte, vid. González Cordero 1999. El templo moderno estaba construido con ladrillo y tapial, salvo los cuatro arcos góticos de la estructura, la portada y las esquinas, que se levantaron con sillares de granito y, ocasionalmente, de mármol, expoliados posiblemente en las necrópolis adyacentes y de las que seguramente recibió la ermita su 
epitafio de una Madre à una hixa, que se le murio de siete años". Como bien notó el editor de la carta, este epígrafe no fue recogido por Hermosilla y, consecuentemente, tampoco fue censado por Hübner y los editores posteriores. ${ }^{18}$ Además, el humanista añadió otro detalle que no puede sino corresponder a la misma inscripción: al describir el significado de las siglas finales del célebre epitafio que acabó en su poder y que, tras diversas vicisitudes, está ahora depositado en el Museo de Toledo, refiere cómo "en la piedra, que está en la hermita esta entero desta manera D. S. F. C". ${ }^{19}$

De estos datos se puede suponer que lo que le enseñaron a Gómez de Castro fue un monumento de mármol, seguramente incompleto, y en el que leyó:

- - - - - / [- - ] an(norum) VII / mater filiae $\beta d(e) \cdot s($ uo $) \cdot f($ aciendum $) \cdot c($ uravit $)$

\section{b) Arcavica}

Aproximándose a Talavera la Vieja desde el oeste, Gómez de Castro describió de este modo el paisaje que se le presentaba:

este mismo día que partí de Almaraz después de salir de una espesura junto con una granja de los Frailes de Guadalupe, se descubrió una Vega de más de media legua llena de retamas, viznagas, salzes enanos otras matas desta manera. Al cabo de ella están unos cerros baxo de los cuales corre el río Tajo, el qual es causa de toda la frescura de aquella vega. Encima de los Cerros están las Ruinas de aquel lugar el qual creo yo que antiguamente se llamó Arcavica por razón de una columna que allí se descubrió la quál yo tengo en mi poder. ${ }^{20}$

La granja de los Frailes de Guadalupe se encontraba al sur de Peraleda de la Mata, en la Granja de Alarza, donde aún hoy "frailes" es un término frecuentemente repetido en la toponimia local. Los cerros a cuyos pies corre el Tajo es el escarpe de la orilla izquierda del río, sobre el que se emplazaba Talavera la Vieja, cuyas ruinas antiguas Gómez de Castro creyó que correspondían a Ercavica por el hallazgo de una columna que declara poseer; tal letrero no parece haber sido registrado hasta ahora.

\subsection{Entre verdades y mentiras}

A fines de 1578, la villa de Talavera la Vieja incluyó en la respuesta "al capitulo treynta e uno" (la referida a los edificios existentes en la localidad) de la llamada Relación de Felipe II o Descripción de los Pueblos de España la siguiente noticia:

advocación. A mediados del s. XVIII, cuando Hermosilla visitó el edificio, ya estaba abandonado y sin techo y medio siglo después había pasado a usarse como cementerio.

18 Sánchez Cantón 1927, 224, n. 2.

19 Gómez de Castro 1572, f. 100v; CIL II 934; Abascal Palazón 2013, 28-29. Al reseñar la carta de Gómez de Castro, Hernando Sobrino $(2009,399)$ apuntó que las siglas podrían pertenecer a la otra inscripción que, con toda seguridad, estuvo en la ermita de los Santos Mártires, la de Pompeia Inventa, pero hay sustanciales diferencias entre ellas, como puede comprobarse infra.

20 Gómez de Castro 1572, f. 98v. Columna aparece escrito “colonia” en el Ms. de la BNE, que Sánchez Cantón 1927, 223, transcribió como "colunia". En la copia de la Biblioteca pública de Cáceres, aproximadamente contemporánea de la de Madrid, aparece como "coluna". 
Y que ansimismo hay muchas piedras rromanas labradas en quadra que servian de sepulcros, y en ellas escritos la rrazon y epitafio y an oido dezir que entre ellos a abido dos uno de los cuales está en la hermita de los martires desta villa el qual dize ponpeia ynventa con cierto numero de tiempo que en esta señalado y el otro en latin muy elegante dezia en sustancia: Aqui yaze la desdichada sierva Tita que por avaricia mato dos hijos suyos Tu que pasas si piadoso eres mira esto. Y que demas de este letrero ay otros muchos que en el mes de mayo deste presente año de setenta y ocho vino ber Ambrosio de Morales consejero de su Mag(estad) el cual podra dar mejor rrazon de d(ic)ha causa por de su facultad. ${ }^{21}$

El paradero del primer epígrafe debió haberse olvidado al tiempo de la respuesta porque no lo nombra ninguno de los posteriores visitantes. De hecho, la primera noticia impresa sobre él reproduce lo dicho en el memorial añadido por José de Cornide al informe presentado por Hermosilla a la Academia de la Historia tras su viaje literario al lugar; y de Cornide pasó a Hübner, que se convirtió en la principal autoridad sobre el documento ${ }^{22}$ hasta que, a comienzos de la década de los noventa del pasado siglo, la sequía provocó una extraordinaria bajada del nivel de las aguas del lago, descubriéndose que la lápida seguía donde estaba hace cuatro siglos, en la ermita de los Santos Mártires, pero colocada como umbral del acceso lateral al edificio cuando éste comenzó a usarse como cementerio, lo que puede explicar su secular invisibilidad. El monumento fue descubierto por Santos, quien fue incapaz de leerlo y, por lo tanto, relacionarlo con la noticia de 1578; sin embargo, debe considerarse como editio princeps la de González Cordero. ${ }^{23}$

Se trata de una estela de granito claro, conservada casi en su integridad, a falta de la parte superior y el lado izquierdo de la cabecera, que probablemente tuvo forma redondeada; es también notable el desgaste de la arista frontal derecha. El remate superior conserva parcialmente un motivo decorativo inusual en la zona: una moldura incisa de forma lenticular con pies en ambos extremos y de cuyos filetes inferiores parten sendos collares de pequeñas esferas, quizá la representación esquemática de una corona floral. El epígrafe se escribió con capitales cuadradas de forma regular, pero factura descuidada, que miden entre 9 y $8 \mathrm{~cm}$; las letras finales de los renglones segundo a quinto están parcialmente obliteradas o se han perdido por completo debido al desgaste antes mencionado.

Tras su descubrimiento y en fecha imprecisa, la estela se trasladó desde el lugar de hallazgo hasta Navalmoral de la Mata y ahora se conserva en la Fundación Concha, inventariada como D-6742.1 (Fig. 1).

Pompeia / Inventa $\beta$ an(norum) $L V \cdot h($ ic) s(ita) e(st) / s(it) t(ibi) t(erra) l(evis) . Pom/peia Cast [a] to d(e) s(uo) f(aciendum) c(uravit)

21 Ms. Escur. J-I-13, ff.. 436r-441r.

22 Cornide Saavedra 1796, 388, ad Hermosilla y de Sandoval y Rojas 1796, de donde CIL II 935, con la ortografía del nombre corregida. Refieren a éste Hurtado de San Antonio 1977, 215, n 478; Salas Martín 1985, 66, no 11.

23 Santos Sánchez 1993, 55-56, nº 7; González Cordero 2001, 133-134, nº 24 (=HEp 11, 2001, $134=H E p O L$ 24509 , con foto). Vid. Esteban Ortega 2019, 40-41, n⿳ 1360 , con fotografía de la lápida y sin novedades respecto a los anteriores. 


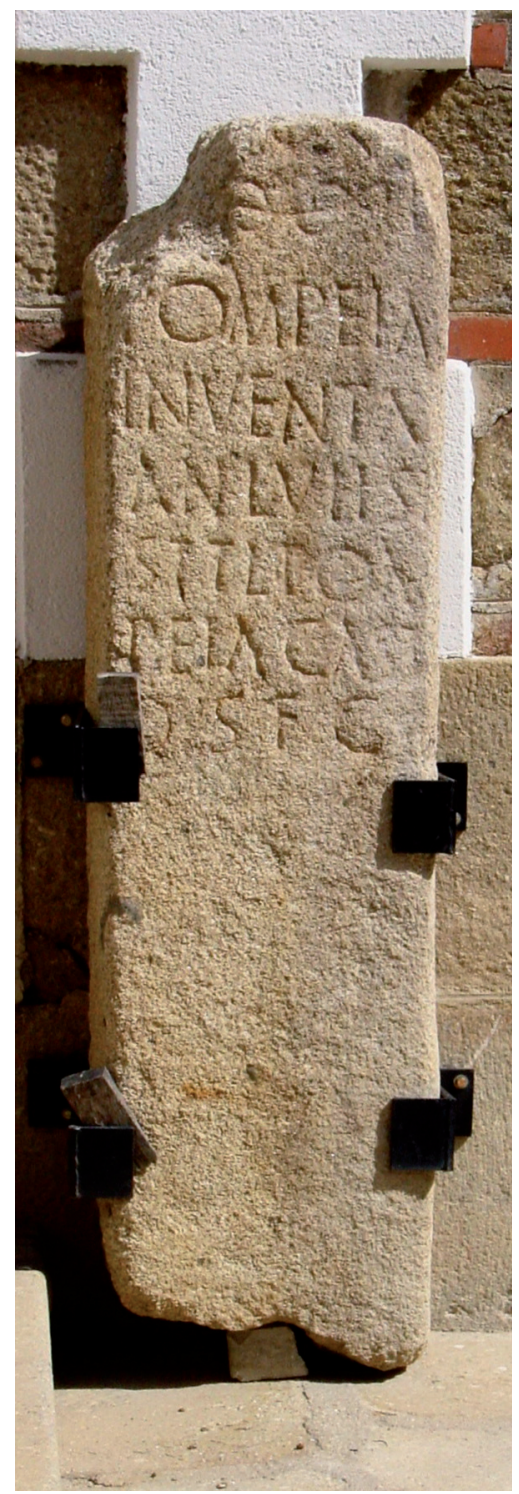

Fig. 1. Epitafio de Pompeia Inventa (C A. Gónzález Cordero 2012).

5: C[- - ], González Cordero, que completó, dudando, como C[aesia?]; Ca [- - -], Esteban; pero tanto en la autopsia como en la foto que adjunta se ve con claridad la -A final del cognomen.

Lo novedoso es que esta lectura ya estaba constatada hace cuatro siglos, cuando en el quinto volumen de su inacabada Historia eclesiástica de España, Jerónimo R. de la Higuera escribió lo siguiente (Fig. 2):

Nunc agendum de ruinis Obilensis oppidi, quod Talavera vetus dicit distans 32 millibus passum a Talavera flumine secundo in cuis vestigis insunt (...) Hallanse aqui piedras escritas (sic) et sepulchra more Romano fabricate sic: 
POMPEIA INVENTA. POMPEIA CASTA.

HAEC EST INFELIX SALVA TITA.

QUAE PER AVARITIAM FILIOS SUOS OCCIDIT ${ }^{24}$

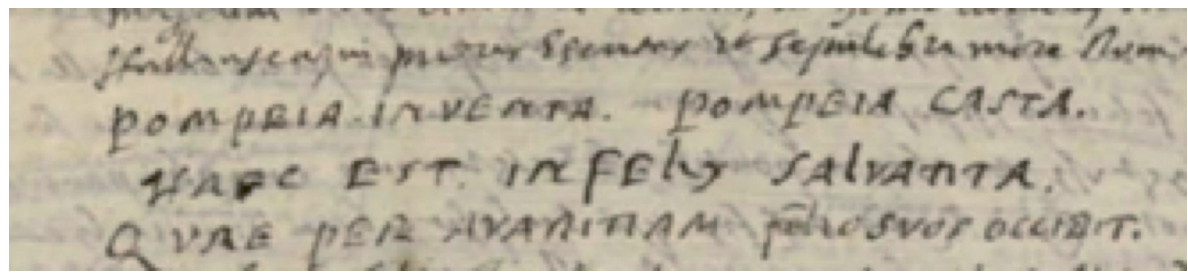

Fig. 2. Fragmento de la Historia eclesiástica de España, tomo V, Ms. BNE 1642 (s. XVI), f. 196v (C Biblioteca Nacional de España).

Es evidente la similitud con lo referido en la encuesta Real, solo que el escritor jesuita añadió a la primera inscripción el nombre pleno de la dedicante de la estela y transmitió “en elegante latín” lo que la otra fuente parafraseó en román paladino. Aunque Hübner supo de este testimonio, omitió incluir el nombre de la dedicante por la fama de mendaz que atribuía a J. de la Higuera. Ahora, el monumento original reivindica al historiador toledano, cuyos escritos no solo contienen textos ex ingenio suo, sino también información veraz y de primera mano, como se ha comprobado en otras ocasiones. ${ }^{25}$ Hübner, en cambio, acertó relegando el texto de la madre parricida al grupo de las inscripciones de dudosa autenticidad, por ser una copia imperfecta y abreviada de un letrero encontrado aparentemente en Roma y que, a su vez, se inspiraba en un escolio de Juvenal. ${ }^{26}$

\subsection{Las perdidas de Hermosilla}

Ya se ha mencionado que otro ilustre visitante de Talavera la Vieja fue Ignacio de Hermosilla y de Sandoval y de Rojas, presbítero y miembro de la Real Academia de la Historia, quien presentó a ese docto cuerpo en 1762 los resultados del examen de las antigüedades del lugar, que había llevado a cabo a su costa y en compañía de un canónigo de Talavera de la Reina y un dibujante. ${ }^{27} \mathrm{Y}$ lo cierto es que lo más interesante de su exposición, cuando apareció impresa en 1796, son las siete estampas con 28 excelentes dibujos de objetos y construcciones antiguas de Talavera. Muchos de los grabados corresponden a inscripciones, de las que se da información sobre sus

24 Higuera s. XVI, f. 196v. Este autógrafo, escrito en latín y español y con letra poco clara, está disponible en http://bdh-rd.bne.es/viewer.vm?id=0000039845\&page=1http://www.bne.es/es/Micrositios/Guias/Inventario Manuscritos/resources/docs/invgenmss05x1x.pdf\#page=49 [consultado el 10 de abril de 2018]. El Ms. contiene abundante material epigráfico, vid. Hernando Sobrino 2009, 139-141.

25 Hübner 1869, XVII, 44. Una visión más matizada del personaje y su obra en Hernando Sobrino 2002, donde se señalan otros casos como el que nos ocupa, donde se describen epígrafes que no aparecen en otros antiquiores y que han quedado contaminados por la mala fama de su editor; vid. González Germain 2011, 274-276, disponible en https://ddd.uab.cat/pub/tesis/2011/hdl_10803_83977/ggg1de1.pdf [consultado el 10 de octubre 2019].

26 CIL II 96*; sobre el origen de este falso y su tradición, cf. González Germain 2015.

27 Hermosilla y de Sandoval y Rojas 1796, cuyo Ms. CAICC/9/3931/01(03) se conserva en el Gabinete de Antigüedades de la Real Academia de la Historia, disponible en http://www.cervantesvirtual.com/nd/ark:/59851/ bmc001n7 [consultado el 25 de octubre de 2019]. Sobre las fechas y circunstancias de sus viajes (hubo una segunda visita en 1774) y las vicisitudes de la publicación de su memorial, vid. Medrano 1997. 
medidas, lugares de hallazgo y otras circunstancia de interés. ${ }^{28}$ Pero Hermosilla no era epigrafista y dejó que las imágenes de las inscripciones hablasen por sí mismas, lo que no se cumple en el caso de las piezas deterioradas.

\section{a) Un ara sin propósito}

Una de estas es la que la que aparece en la "Estampa segunda" y que se describe así: "últimamente la de la let. $J$ es otro pedazo de ara de un pie y quarto en quadro, que de una misma viña hice llevar a la casa del mismo teniente cura: ${ }^{29}$ todas son de piedra berroqueña" (Fig. 3). El testimonio de Hermosilla fue refrendado por los apuntamientos que el médico y anticuario pacense Agustín Francisco Forner y Segarra tomó durante su visita a Talavera la Vieja y que según Cornide, se reducen a que "en la de la letra J solo añade un punto entre la A y la $\mathrm{M}$ de la segunda línea, y dice que es una ara, y que por las dos letras de la primera línea se puede sospechar fue cumplimiento de algun voto hecho á la diosa Diana". ${ }^{30}$ A partir del dibujo y los testimonios de Hermosilla y Forner, Hübner compuso la correspondiente entrada del $C I L$, reproducida por posteriores editores porque el altar se da por perdido. ${ }^{31}$

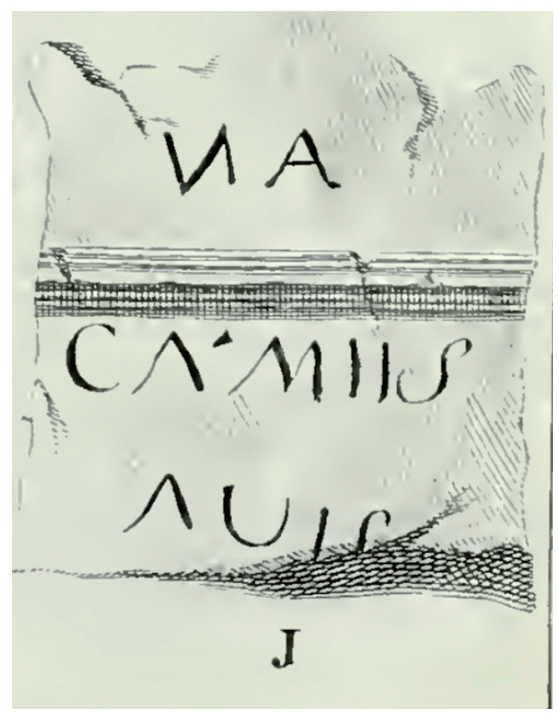

Fig. 3. Figura J de la estampa cuarta de Hermosilla 1796 (dominio público).

28 Las láminas pueden verse en https://archive.org/details/memorias01 real/page/n587 [consultado el 25 de octubre de 2019].

29 El personaje en cuestión fue el presbítero don Sebastián Rufo Morgado, del que Hermosilla (1796, 352) escribió "que me acompañó con mucha fineza, es muy aplicado y zeloso, aunque sin los principios necesarios para el conocimiento de estas antigüedades"; los hallazgos del académico siguieron en el patio de la casa del cura hasta mediados del pasado siglo.

30 Hermosilla 1796, 349, y A. F. Forner y Segarra, Primera parte de las antigüedades de Extremadura, Ms. 1793, apud Cornide Saavedra 1796, 391. Cerrillo Martín de Cáceres ha editado recientemente las notas de Forner y Segarra (2017).

31 CIL II 933; Hurtado de San Antonio 1977, 214, n 476; González Cordero 2001, 132, n 22; Esteban Ortega 2019 , $54, \mathrm{n}^{\circ} 1377$, este último sugiriendo que el epígrafe puede ser un altar anepígrafo que se conserva inventariado como D-6708 en la Fundación Concha de Navalmoral de la Mata, pero vid. infra. 
Sin embargo, a comienzos de la primera década de este siglo, se dio la oportunidad de describir y fotografiar en Jarandilla la parte superior del ara de granito, golpeada y erosionada en sus esquinas. Arriba tiene restos de un frontón triangular, flanqueado por pulvini. En medio del frontón parece apreciarse un pequeño creciente lunar unido por un mínimo rasgo vertical al surco que aparenta ser la base del triángulo. En la parte inferior de la cornisa asoma una doble moldura que da paso al fuste. Medidas: (27) x 27 x $24 \mathrm{~cm}$. Letras capitales rústicas muy mal trazadas, de $4 \mathrm{~cm}$. Interpunción redonda (Fig. 4).

Por lo que contó entonces su propietario, la pieza perteneció a Anastasio Bayán, un vecino de Talavera la Vieja, ya fallecido, que vivía en la casa de los herederos del teniente-cura, a quien Hermosilla confió la custodia de éste y otros epígrafes. Cuando Bayán se vio forzado a abandonar su pueblo para trasladarse a Navalmoral de la Mata, se llevó también las antiguallas que había en el patio. Más tarde, regaló este fragmento a su actual propietario. Fue Madruga quien se dio cuenta en 2012 de que se trataba del mismo monumento dibujado en la Noticia de Hermosilla y quien ofreció, a partir de la fotografía, una primera transcripción, que hemos modificado levemente

$$
+A / C A \cdot M++\beta[-] \underline{A V I S} / \ldots
$$

MA / CA - MIIS / AVIS / - - - - -, según CIL y sucesivos editores. Tanto Forner como Hurtado San Antonio suponían que era un altar votivo, pues en la lín. 1 el primero entendía [Dia]na y el segundo, con dudas, propuso Ma[rti]. La lectura de

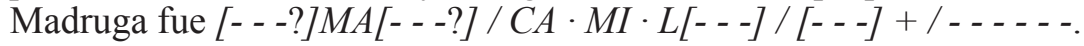

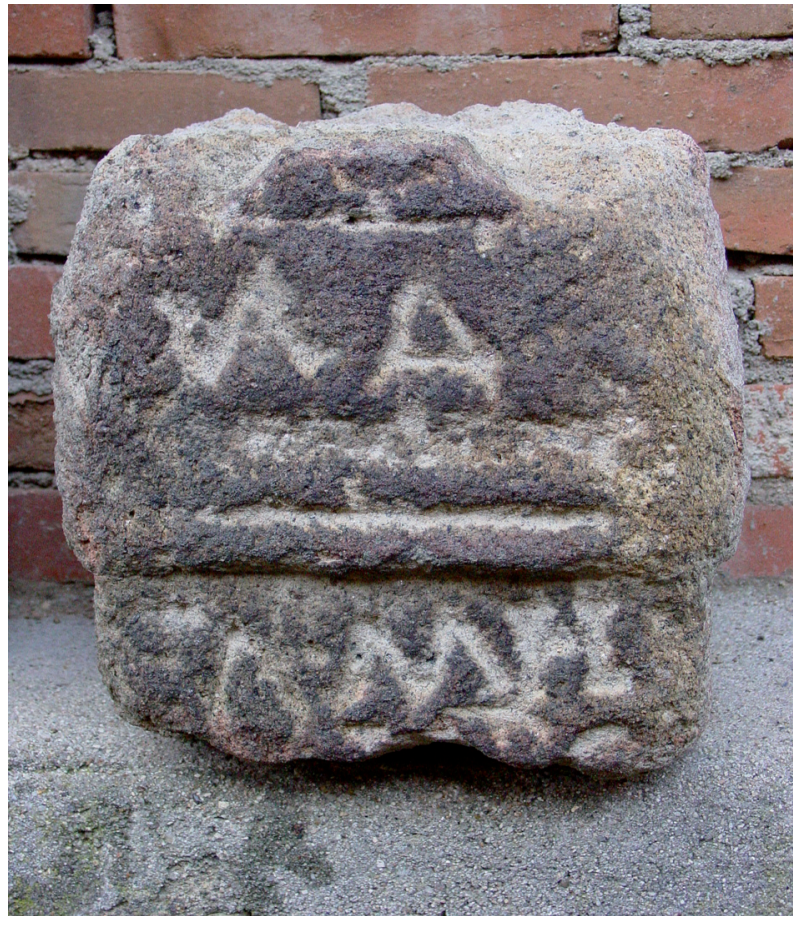

Fig. 4. Fragmento de ara (C A. Gónzález Cordero 2012). 
La primera línea es intrigante porque ni en el dibujo de Hermosilla ni en la foto se aprecia el primer rasgo de la pretendida $\mathrm{M}$ y en ambas imágenes es claro que no hay rasgos visibles antes o después de los dos signos, que parecen centrados en el espacio disponible. Tampoco puede ser una $\mathrm{N}$, porque su forma es refleja; quizá pueda tratarse entonces de un nexo VAL, pero en tal caso ignoramos a qué equivale la A y la relación de este renglón con el siguiente, en el que son seguras las tres primeras letras y la interpunción que separa los emparejamientos, aunque el grupo II del dibujo de Hermosilla también podría ser $\mathrm{H}$; el desconchado en el borde derecho parece la huella negativa de una S. De la tercera línea sólo quedan los ápices de las letras, que son compatibles con lo que era visible hace más de doscientos años, salvo que la I lleva un travesaño propio de una $\mathrm{T}$ y el bucle superior de la $\mathrm{S}$ final se corresponde mejor con una $\mathrm{O}$ o una $\mathrm{C}$.

En definitiva, y a pesar de su reaparición, la condición del letrero es tan lamentable que el epígrafe sigue siendo tan ininteligible como lo era hace doscientos años.

\section{b) La edícula con prótomo}

El más vistoso de los monumentos descritos por Hermosilla es el que ocupa la parte superior de la "estampa quarta" y que se describe del siguiente modo (Fig. 5):

En la casa de ayuntamiento hay suelta otra ara sepulcral de marmol finísimo de casi dos pies de ancho y tres y medio de alto y sin embargo de estar muy destruida, se perciben en baxo relieve la figura de un joven, los vestigios de una inscripción y los ornamentos que se manifiestan en la estampa $4^{\mathrm{a}}$, let. P. trabajados con todo el arte, primor y delicadeza que se admiran en los preciosos restos que hay en Roma del siglo de oro de las artes. A los lados están de baxo relieve un vaso y una especie de lámpara, como se ven en la misma estampa. El vulgo creía que el joven esculpido en esta ara era el ídolo que adoraban los gentiles, por esto lo han destruido y desfigurado á pedradas, dexando menos ofendidos los adornos. ${ }^{32}$

La descripción manuscrita de este monumento que hizo Forner, de quien ya se ha dicho que visitó Talavera la Vieja veinte años después del segundo viaje literario de Hermosilla, fue parafraseada por Cornide de este modo:

Quanto á la estatua de que habla el señor Hermosilla en la pagina 9 de su memoria, cuya copia nos da en la estampa IV letra P cuyo diseño corrige en su segunda memoria, dice Forner que en su tiempo se hallaba en el zaguán de la casa de ayuntamiento puesta en el suelo, que representa el busto de un varón con capa, pero que como la inscripción está borrada, no se puede conocer á quien pertenecia, y que es verisimil fuese de persona distinguida del pueblo; yo mas bien creo por los instrumentos de sacrificio que el señor Hermosilla dice se hallan en sus dos lados, que sería de alguna deidad á quien diesen culto los de Talavera. ${ }^{33}$

A partir de lo escrito por Hermosilla y Forner apud Cornide, Hübner catalogó un pretendido epígrafe, que sus dos fuentes afirman taxativamente no existía porque de

32 Hermosilla y de Sandoval y Rojas 1796, 351.

33 Cornide Saavedra 1796, 392. 
la inscripción solo quedaban "vestigios" o "está borrada". Y tanto Cornide como Hübner insisten en que Hermosilla describió el prótomo como femenino, siendo que éste último se refiere en dos ocasiones al "joven", lo que concuerda con Forner, quien se refiere a un "varón con capa". ${ }^{34}$

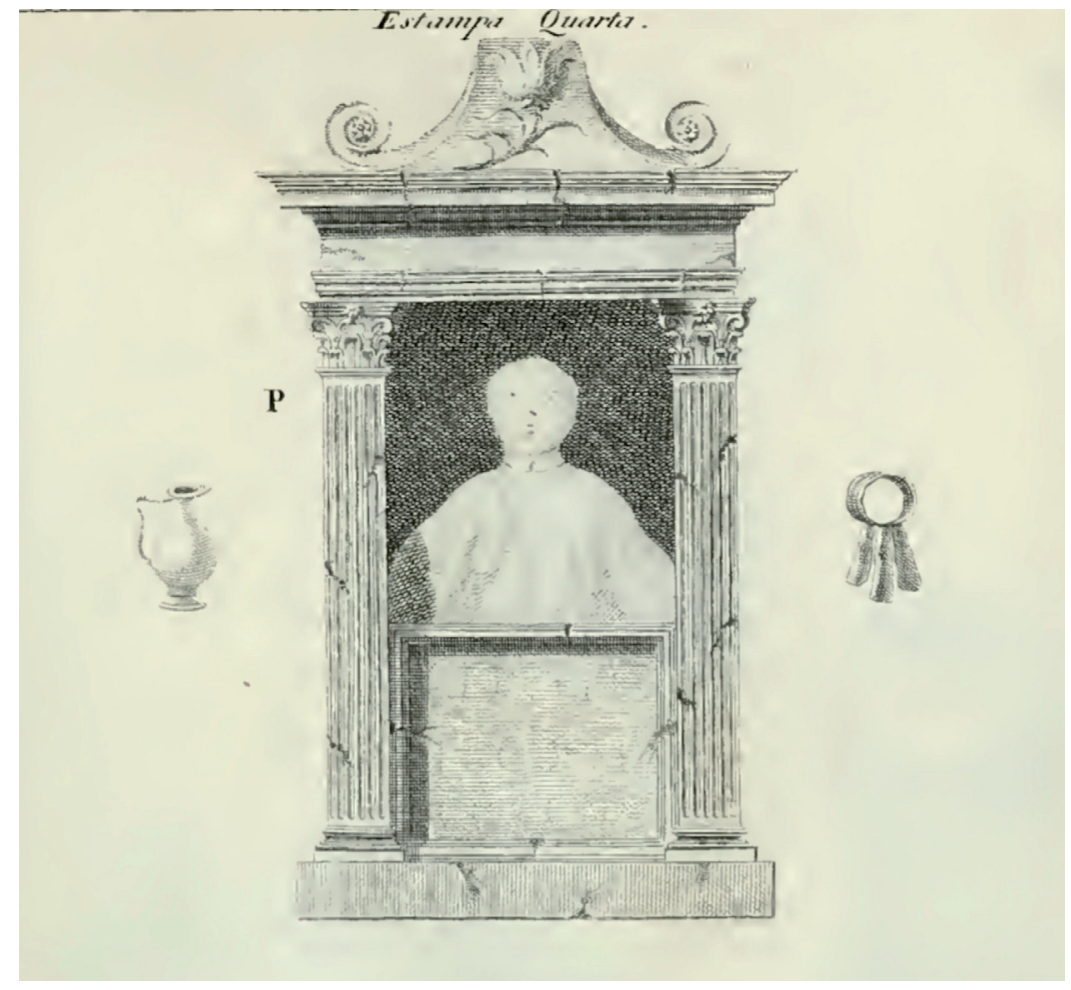

Fig. 5. Figura P de la estampa cuarta de Hermosilla 1796 (dominio público).

Disponemos de dos fotografías (Fig. 6), tomadas hace unos cuarenta años por D. Leandro Garrido, maestro de Navalmoral de la Mata, y que muestran dos trozos de un monumento funerario insculpido que podrían corresponder a la porción derecha del que vio Hermosilla; desgraciadamente, se ignora el lugar y las circunstancias en que se tomaron esas dos vistas y, por supuesto, su actual paradero. Las razones para relacionarlo con la imagen de la Noticia del académico son por ello las similitudes formales entre ellas. Nótese que el monumento del grabado parece ser de mucho porte, pero las dimensiones que se le asignan -"casi dos pies de ancho y tres y medio de alto"- equivalen a los más o menos 90 x $50 \mathrm{~cm}$ de la pieza fotografiada, porque su altura solo se muestra en la vista lateral, donde los dos fragmentos aparecen en posición correcta. Ciertamente difieren las proporciones entre el busto y el campo epigráfico, pero se desconoce hasta qué punto el dibujo de Hermosilla se hizo a escala y ateniéndose a lo que se veía en la piedra o se buscó la expresividad. El modo en que se representó el busto y el triple mango de la trulla, que es propio de lo que

34 CIL II 939 lo describe como protome feminae y da el siguiente texto CVIICIII / FIICICII / INSTTL; ambos errores se reproducen en Esteban Ortega 2019, 54-55, nº 1378. 
el académico describió como "especie de lampara", parece indicar que se primó lo vistoso sobre la exactitud. En cambio, grabado y fotografía coinciden en que la figura iba flanqueada por pilastras estriadas, cuya base se aprecia en la esquina inferior derecha de la foto frontal y, de forma más nítida, en la vista lateral; y, por supuesto, hay coincidencia en la colocación y orientación de la trulla. Finalmente, el mal estado de conservación del frontal y de la decoración lateral que se aprecia en las fotos puede explicarse porque, contraviniendo la Ordenanza municipal antes mencionada, debieron de sufrir con la costumbre de apedrear las esculturas antiguas, en la creencia de que eran los rostros de los dioses adorados por los paganos.
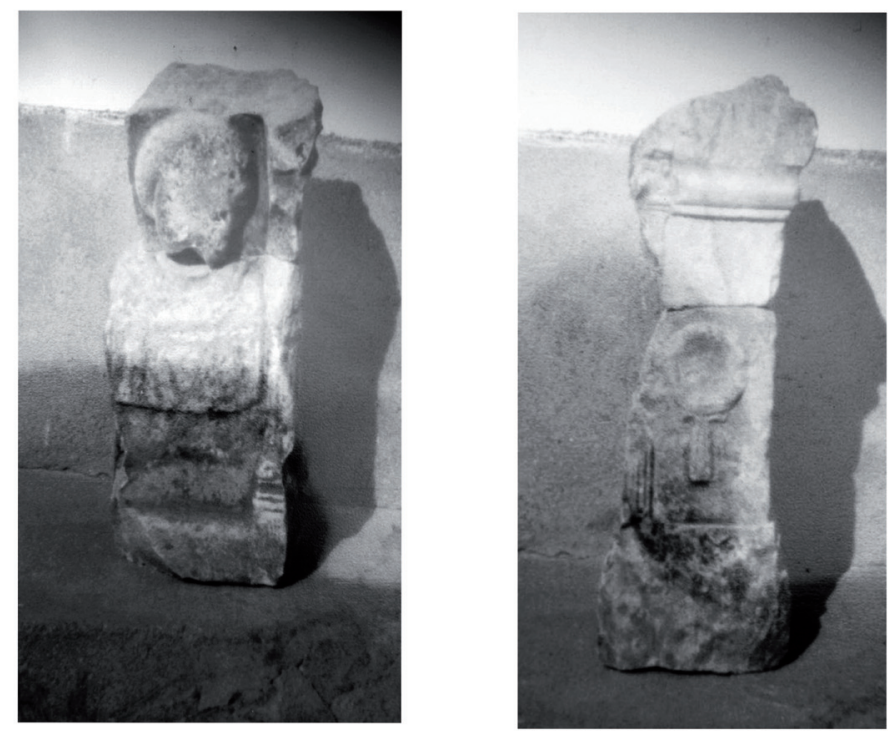

Fig. 6. Vista frontal y lateral del epitafio con busto y decoración lateral (C L. Garrido).

\subsection{A lacu resurgentes}

A pesar de encontrarse a una decena de metros por debajo del nivel nominal del pantano, las ruinas de Talavera la Vieja afloran a la superficie en épocas de sequía o durante los desagües programados del embalse. La acción del agua y el expolio de los derribos del lugar ofrecen ocasionalmente nuevos descubrimientos. Las piezas siguientes, salvo mejor opinión, son inéditas y se descubrieron durante las periódicas exploraciones de las orillas del pantano y, cuando el nivel de las aguas lo permite, de las mismas ruinas.

\section{a) Fragmento de altar votivo}

Parte inferior de un ara de granito, que ha perdido la corona y una parte indeterminada del neto. La transición entre éste y la base está señalada con un friso serrado. Mide (30) x 25 x $18 \mathrm{~cm}$. Letras: $6,5 \mathrm{~cm}$. Vista, descrita y fotografiada en septiembre de 2012 entre las ruinas de la ermita de los Santos Mártires, donde sigue (Fig. 7). 


\section{- - - - - / [v(otum) s(olvit) l(ibens)] / m(erito)}

Se ofrece la más probable restitución, pero puede tratarse también de $m$ (onumentum), inusitado en la zona, o de una dedicatoria a Júpiter de la que solo queda la sigla del último de los epítetos comunes.

Vistas las dimensiones del fragmento, debió tratarse de un ara esbelta y de cierta altura, similar a las que justificaron el aserto de A. Gómez de Castro de que en "otras casas del lugar donde, que por estantales, que por quicios ai muchas piedras escritas". ${ }^{35}$

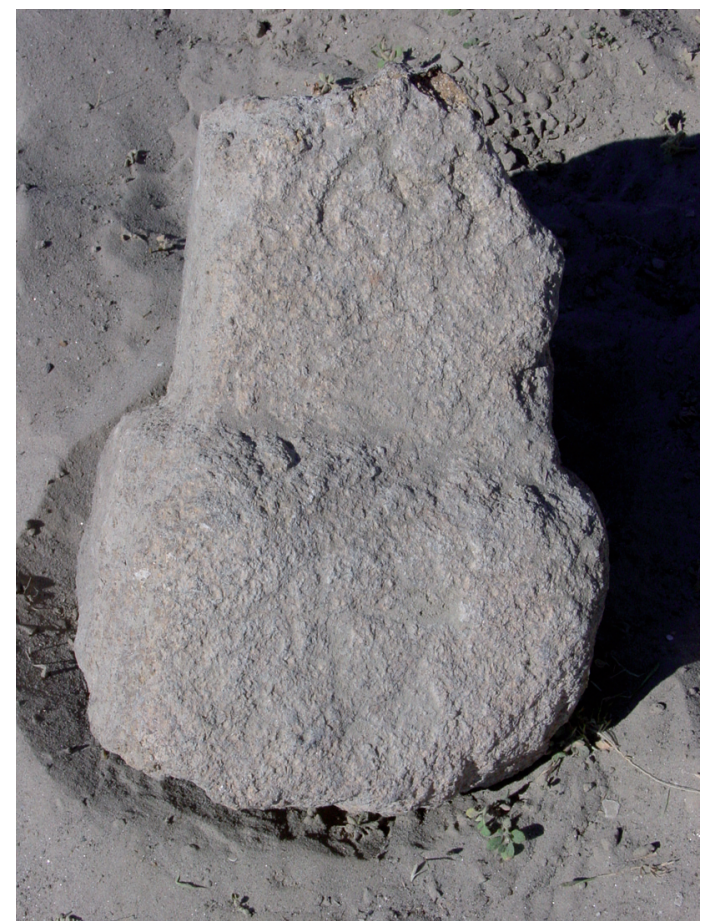

Fig. 7. Fragmento de altar votivo (C A. Gónzález Cordero 2012).

\section{b) Epitafio de un emeritense}

Bloque de granito oscuro que fue parte de un epitafio, retallado posteriormente para su empleo como sillar. Sus medidas en el momento del descubrimiento eran (47) x 48 x $28 \mathrm{~cm}$. En pésimo estado de conservación debido a un fuerte golpe en la esquina superior derecha de la cara frontal y alteración superficial causada por la larga inmersión en agua calcificada y por el ataque de las algas. No debe extrañar que las letras, que son capitales cuadradas de $7 \mathrm{~cm}$, estén muy deformadas.

El epígrafe está en un muro de la ermita de los Santos Mártires, colocado con la cara inscrita hacia dentro. Visto, descrito y fotografiado en septiembre de 2012; por lo que nos consta, sigue en el mismo lugar (Fig. 8).

35 Sánchez Cantón 1927, 224. 

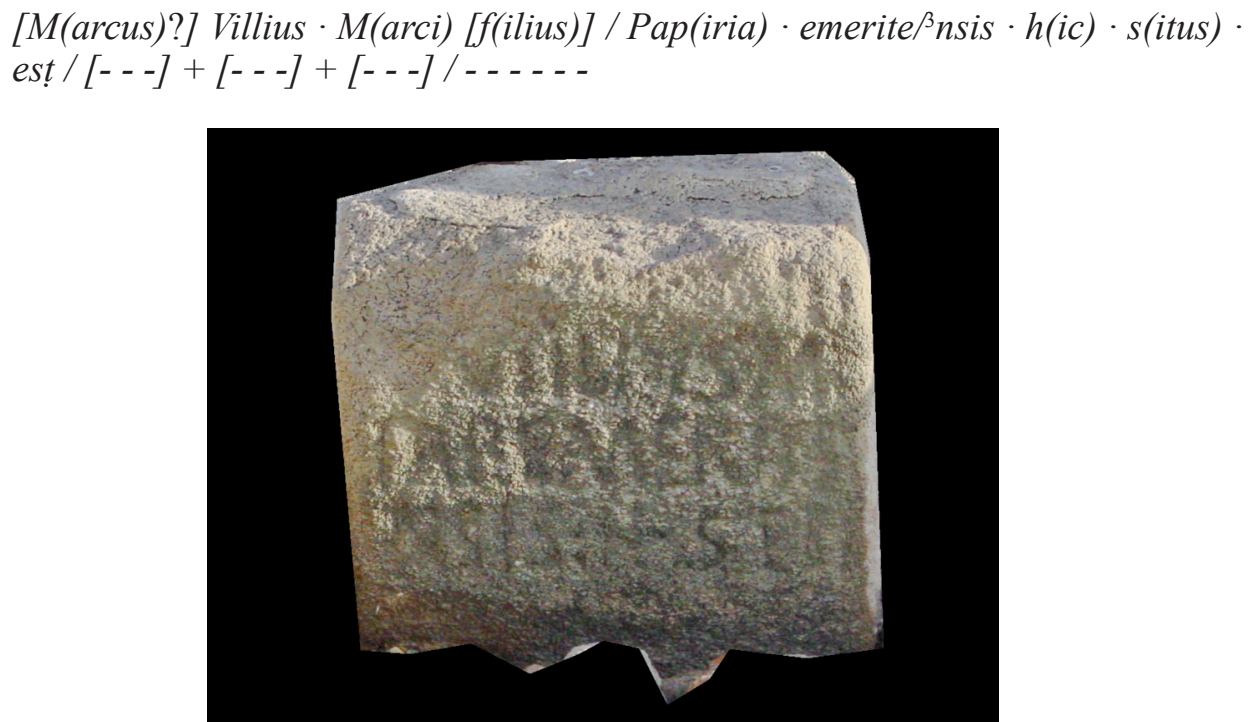

Fig. 8. Epitafio de un emeritense (ㄷ A. Gónzález Cordero 2012).

Falta la letra inicial del primer renglón, por lo que el difunto pudo llamarse [A]villius, muy corriente en la antroponimia lusitana; pero considerando los otros elementos de su nombre, parece más probable que lo perdido fuera el praenomen y que padre e hijo fueran homónimos. Villius es un nombre infrecuente en Hispania, pero está documentado en el vecino Turgalium. ${ }^{36}$ Papiria Emeritensis puede parecernos redundante, pero es lo que cabe esperar por ley y costumbre, como muestran otros testimonios de la propia Augusta Emerita y de su conventus iuridicus. ${ }^{37}$ En la cuarta línea, solo se ven los ápices de un par de letras que deben corresponder a la fórmula sepulcral y quizá también al nombre del dedicante.

Este epitafio es seguramente la consecuencia de una muerte in itinere, que pudo suceder cuando el difunto estaba de paso por el lugar o como consecuencia de cualquiera de los cotidianos motivos que podían llevar a un capitalino a visitar una de las ciudades de la provincia. Se trata del segundo alienus atestiguado en Augustobriga, donde Hermosilla ya vio un epitafio infantil, dedicado por la cluniensis Sentia Acca a quien posiblemente fue su hijo. ${ }^{38}$

La simplicidad del formulario y la expresión del nombre de difunto en nominativo sugiere una fecha temprana, del s. I d.C.

\section{c) Fragmento de placa acéfala}

Esquina inferior derecha de una placa o tabla marmórea, enmarcada por una moldura con dos baquetas y una gola; sus dimensiones actuales son $(15,5) \times(21,5) \times 4,8 \mathrm{~cm}$.

36 Vid. Esteban Ortega 2012, 23, nº 450 (=HEpOL 20449): M. Villius M. l. Philagurius, en La Aldea del Obispo, junto a Trujillo.

37 Augusta Emerita: AE 1952, 117 (=HEpOL 16756); AE 1971, 147 (=HEpOL 20234); HEpOL 28646. Capera: CIL II 823 (=HEpOL 21762).

38 Hermosilla y de Sandoval y Rojas 1796, 349, estampa 2, letra G, de donde CIL II 975 y restantes editores. 
Del epígrafe sobrevive el final de los tres últimos renglones, aunque del primero solo resta la parte inferior de cuatro letras y en el tercero queda una letra completa y el ápice superior de otra. Son capitales cuadradas, incisas con rasgos finos, bien marcados, de buena factura y módulo alargado, de 3,2 cm. Interpunción triangular con ápices desarrollados.

La pieza fue encontrada, descrita y fotografiada en el verano de 2017 en las ruinas de Talavera la Vieja, donde permanece (Fig. 9).

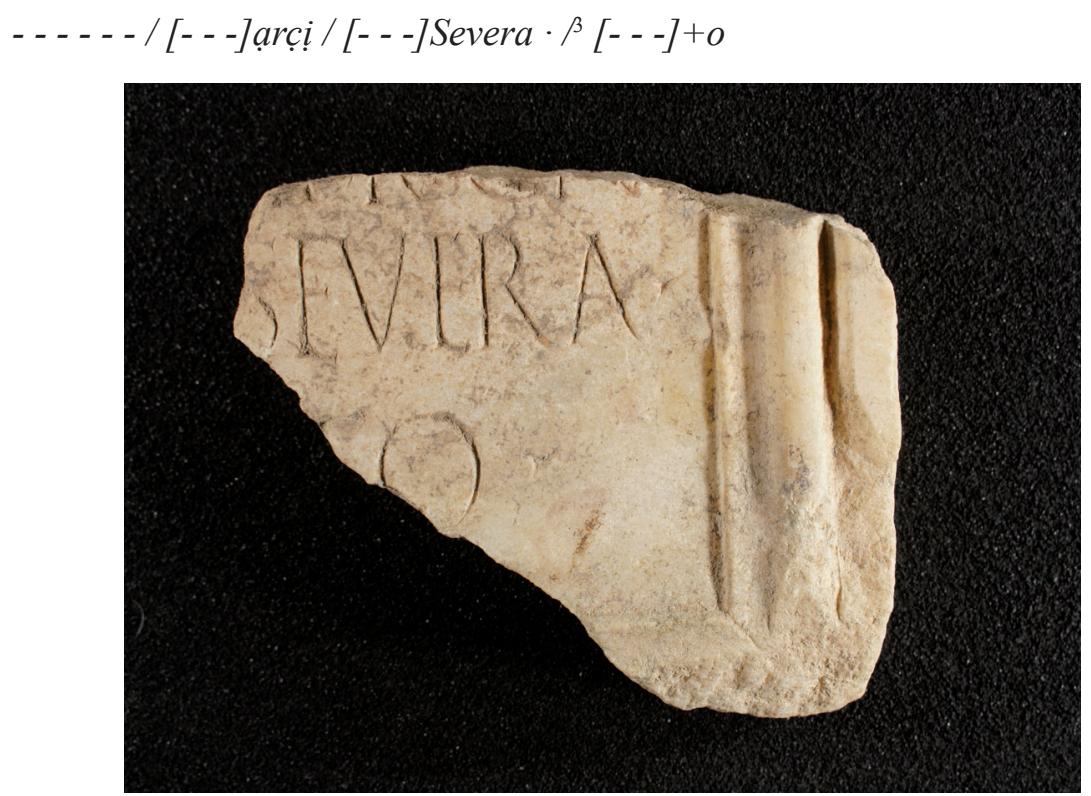

Fig. 9. Placa de mármol acéfala (C A. Gónzález Cordero 2012).

En el primer renglón solo es segura la segunda letra, que no puede ser más que una $\mathrm{R}$; las restantes son inciertas: de la primera sólo queda un rasgo inclinado, compatible con A o M; la tercera es el arco medio-inferior de una $\mathrm{C}$ o $\mathrm{G}$ y el arranque del astil vertical puede corresponder a I, P o T; pero la combinación más probable de todas ellas es [M]arci. En la tercera línea, antes de la $\mathrm{O}$ solo se ve la gracia final de un brazo, que puede corresponder a diversas letras. Por lo tanto, la interpretación más plausible del letrero es que la persona mencionada es la dedicante y la desinencia final de la línea siguiente define su relación con el honrado, maritus, filius o amicus.

\section{d) Altar funerario mutilado}

Parte superior de un altar de granito claro del que se conserva la corona y el arranque del neto. La primera consiste en frontón triangular con roleos, del que solo queda parte del de la derecha, porque el lado opuesto fue arrancado por un golpe. La transición al neto, casi de la misma anchura que la cabecera, se hace mediante un par de molduras, la superior el doble de ancha de la que le sigue y que marca la línea de mutilación de la pieza, de tal modo que solo quedan dos porciones inconexas de la superficie original del monumento. Sus medidas son (41) x 28 x $27 \mathrm{~cm}$. El texto se reparte entre el frontón y el neto; en el primero grabaron tres siglas, mientras en 
el segundo constan dos letras seguras y quizá restos de otra tercera; miden $7,5 \mathrm{~cm}$ de altura. Hallada en las ruinas de Talavera la Vieja y descrita y fotografiada en septiembre de 2012 por González Cordero. Sigue en el mismo lugar (Fig. 10).

$D$ (is) $M$ (anibus) $[s($ acrum $)] / C a[---]+[---] / \ldots$

Claramente un epitafio, ya que en el frontón se grabaron las siglas de la invocatio canónica, de las que quedan la parte inferior de la D y la M, íntegra, mientras que la $\mathrm{S}$ desapareció como consecuencia del fuerte golpe que arrancó el extremo superior derecho del ara. Del epitafio quedan restos de tres letras, de lectura insegura por la erosión: la primera es parte del arco de una $\mathrm{C}$ o $\mathrm{G}$ y más improbable una $\mathrm{O}$ o $\mathrm{Q}$, porque el segundo rasgo, menos visible, es una línea inclinada, propia de A o M, por lo que la secuencia consonante y vocal más probable es la que se ha transcrito. La crux corresponde a la parte superior de un asta vertical con gracia, esto es, una I o L.

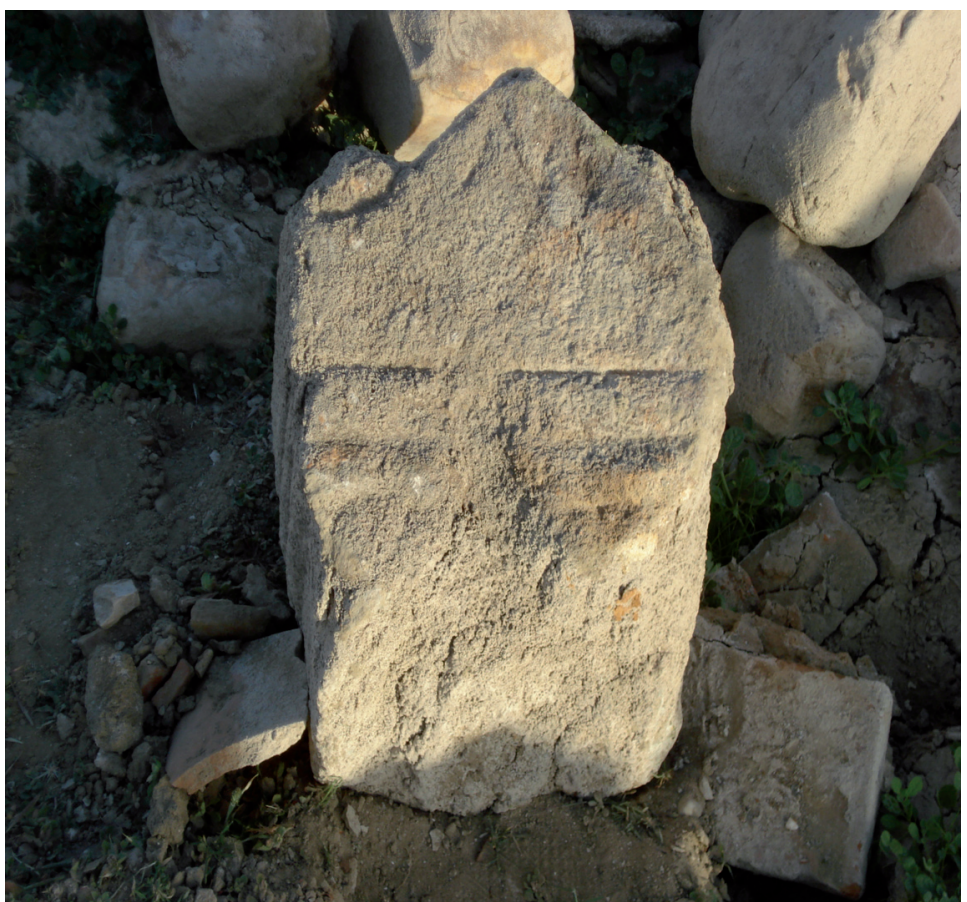

Fig. 10. Cabecera de un altar funerario (C A. Gónzález Cordero 2012).

\section{e) Fragmento de epígrafe con ¿tridente?}

Bloque de granito, de forma semi-cónica y con el frontal alisado; está roto o golpeado en la cúspide, tiene muy rodados los laterales y la basa está también dañada. Mide (54) x 50 x $22 \mathrm{~cm}$. El letrero consiste en dos renglones con letras rústicas de $6,5 \mathrm{~cm}$ y bajo él hay un anagrama de lo que parece la cabeza de un tridente, con el diente central rematado por un brazo horizontal y sin astil. La pieza estaba en el lecho del pantano de Valdecañas, en la zona conocida como "Cañada de los Judíos", en la orilla septentrional del cauce original del río Tajo, frente a Talavera la Vieja (hoy 
jurisdicción de El Gordo), donde existen restos de un área sepulcral aneja a una villa. Encontrada, descrita y fotografiada en septiembre del 2012. Permanece in situ (Fig. 11).

- - - - - / [- - ]AED[- - / - - - $C I N+[---] /$ Ctridens]

En Hispania, el tridente es un símbolo estrictamente asociado a epitafios. Un recuento no exhaustivo de los epígrafes con este signo muestra un modesto agrupamiento en las comarcas noroccidentales de Hispania citerior y casos dispersos en Lusitania, estando el grupo más numeroso en Cárquere, Resende, distrito Viseu, la antigua Civitas Coilarnium, seguido de los cuatro hallazgos en la zona de la Civitas Zoelarum, esto es, Bragança y sus alrededores $;^{39}$ hay también unos pocos epígrafes en el conventus Asturum y dos en el Cluniensis. ${ }^{40}$ Los ejemplos lusitanos son extravagantes respecto al grupo anterior y se reparten en lugares del conventus Emeritensis, Pinheiro, Aguiar da Beira, distrito Guarda, Malpartida de Cáceres y quizá también, Avila.$^{41}$ No hay una explicación satisfactoria sobre el significado del tridente, que tiene connotaciones anfiteatrales, marítimas (clarísimas en el caso del epígrafe de Clunia) y quizá también epicóricas, por su similitud con una vulgar herramienta agrícola. ${ }^{42}$

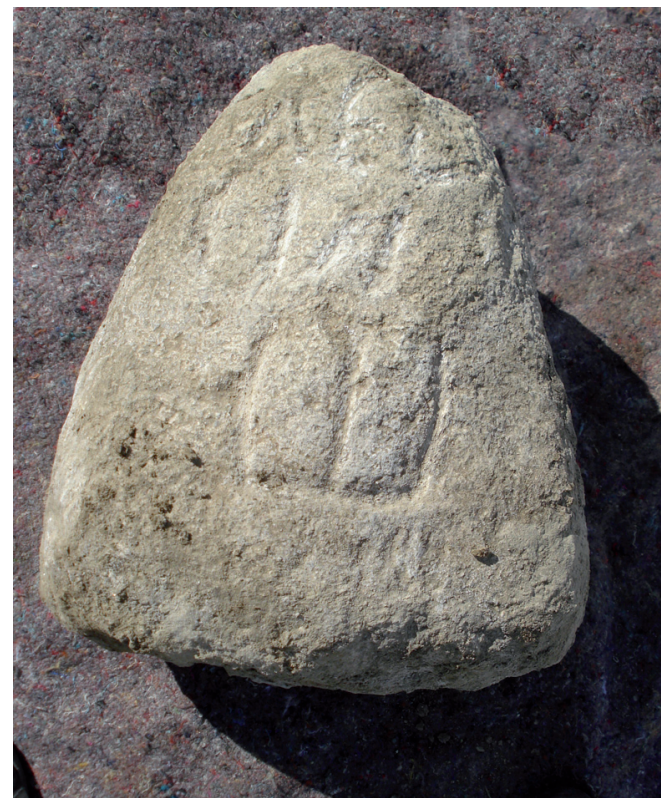

Fig. 11. Fragmento de epígrafe con tridente ( A. Gónzález Cordero 2012).

39 Respectivamente HEpOL 20513-15, 20517-18 y 26026 y Redentor 2002, nº 21, 28, 80 y 82.

40 C. Asturum: en Asturica Augusta (HEpOL 14405), Legio VII (CIL II $5696=$ HEpOL 12016), Paramio (GómezPantoja 2019) y el caso dudoso de Torrefrades, estos dos últimos en la provincia de Zamora (Beltrán Ortega 2016, 299, vol. II, no 276; disponible en https://eprints.ucm.es/39400/ [consultado el 25 de agosto de 2018]); . Cluniensis: en la propia Clunia (CIL II $2807=$ HEpOL 12016) y Belorado (Gorrochategui - Fernández Corral 2016, 280-281, n ${ }^{\circ}$ ).

41 Respectivamente HEpOL 25888 y 23297, y Hernando Sobrino 2005, 116-117, $\mathrm{n}^{\mathrm{o}} 35$.

42 Esta idea, sugerida por Caron 1996, 82, es la que parece más probable a Redentor 2002, 242. 


\section{f) Altar anepígrafo}

Ara de granito blanquecino, rota en dos fragmentos contiguos hacia la mitad del neto y labrada por las cuatro caras, con corona con doble pulvino, cabecera moldurada, fuste liso y un dado simple como basa. Mide 26,5 x 12 x 9,7 cm y es de proporciones esbeltas, pues el fuste ocupa más de la mitad de la altura. No hay indicios de grabación, pero en la parte baja del neto se aprecian restos del revoque de cal o estuco, que pueden sugerir decoración o letrero pintado.

Se encontró en el mismo paraje que el anterior, en la "Cañada de los Judíos"; las noticias disponibles hablan del hallazgo de cuatro aras, colocadas en las esquinas de un entierro de la necrópolis antes nombrada. Se desconoce el paradero de las otras tres, pero ésta fue descrita y fotografiada in situ por González Cordero antes de que se trasladase al Museo de la Fundación Concha, en Navalmoral de la Mata, donde se conserva (Fig. 12).

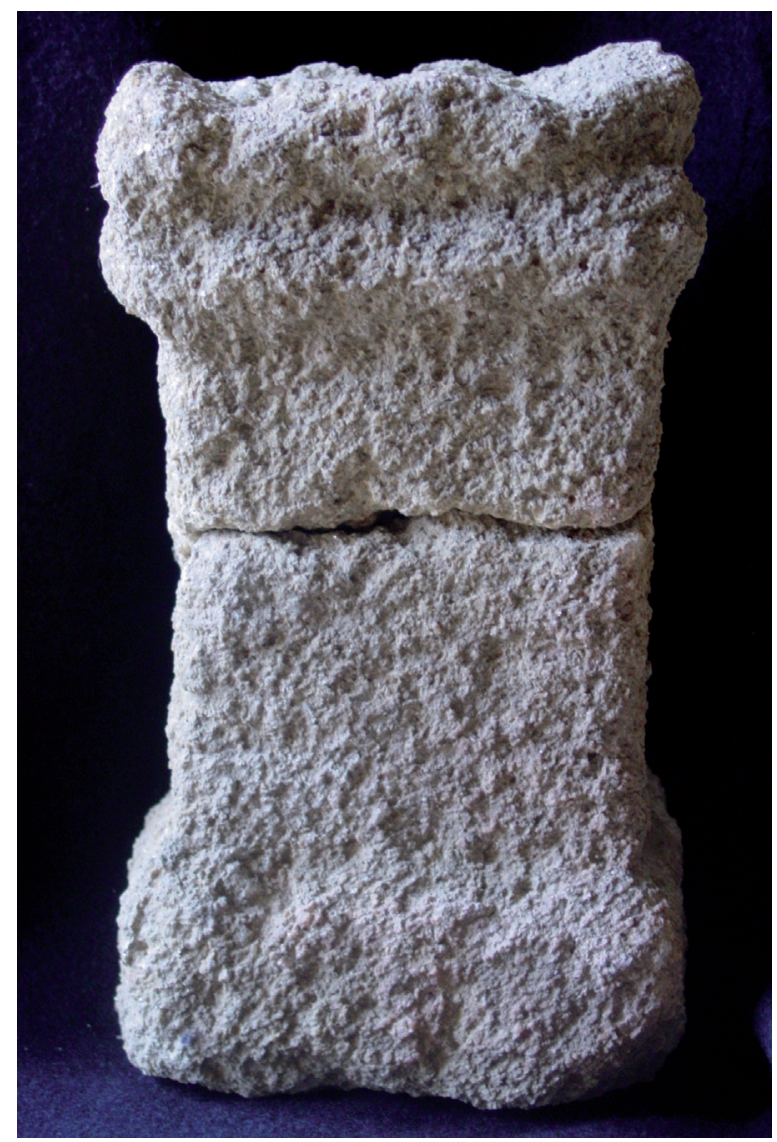

Fig. 12. Altar anepígrafo (C A. Gónzález Cordero 2012).

\subsection{Las ruinas de La Poveda}

A unos $7 \mathrm{~km}$ al sur-suroeste de Talavera la Vieja, en el término de Peraleda de San Román, se encuentran las ruinas del despoblado de La Poveda o Povea, cuyo resto 
más significativo era su templo o ermita del mismo nombre, edificada con materiales expoliados de las propias ruinas de Augustobriga o de construcciones romanas más próximas. A principios del pasado siglo, el estado ruinoso de la capilla obligó al derribo, pero algunas fotografías antiguas permiten conocer su planta y alzado; actualmente solo sobrevive la portada lateral, cuyo estilo data la construcción a fines del s. XV. ${ }^{43}$ Con los restos más aprovechables o significativos del desmonte se formó una escombrera en la que se encontraron los dos monumentos que se describen a continuación.

\section{a) El epitafio de Merope}

$\mathrm{Su}$ primer editor describió este cipo como "de mármol tosco" y además de las dimensiones del monumento y de su paradero tras el hallazgo (ambos datos erróneos), ofreció una fotografía del frontal inscrito en que se ve la corona esquemática de un altar, cuya inscripción estaba encuadrada por una simple línea incisa; tanto la moldura como el letrero aparecen retocados con trazos negros (Fig. 13). A todo ello, acompaña la siguiente transcripción:

$$
\begin{aligned}
& D(\text { is }) \cdot M(\text { anibus }) \cdot s(\text { acrum }) / \text { Sacra } \beta \text { fecit / MERO / PEMAI / }{ }^{6} \text { SVENI / IVSMIN } \\
& / \cdot L \cdot{ }^{\rho} F \cdot C \cdot T \cdot
\end{aligned}
$$

Aunque su editor lo identificó correctamente como un epitafio, la peregrina explicación del mismo mostraba que no entendió su contenido. ${ }^{44}$

Más tarde, González Cordero localizó el monumento donde lo había visto Santos, lo describió con más precisión en lo relativo a sus dimensiones (115 x 33 x $25 \mathrm{~cm})$, el material en que se talló -que es granito amarillento-, y las características del letrero, cuyas capitales cuadradas son de factura profunda, pero de trazo irregular y miden unos $7 \mathrm{~cm}$; la interpunción se limitó a las siglas, que en la lín. 8 son meramente estéticas; la hedera de lín. 7 marca apropiadamente la segunda cláusula del epitafio. El texto se lee bien, salvo en las lín. 6-7, donde el desgaste dificulta la legibilidad. González Cordero examinó el altar en el lugar donde lo encontró Santos, amontonado con fustes de columna, basas de sillares y la estela que se describe a continuación, al lado de las ruinas de la ermita. Salvo mejor opinión, sigue en el mismo lugar del hallazgo.

González Cordero no se apartó de la transcripción anterior pero sí discrepó de Santos respecto a la función del epígrafe, que consideraba votivo. Indudablemente, la invocatio a los Manes corresponde a un epitafio, pero la ausencia de fórmulas sepulcrales, la mención sacra y la difícil secuenciación de las lín. 4 a 6 son causa de incertidumbre.

43 Quijada González 1999, 18 (disponible en http://es.calameo.com/read/004677820b57a149bab90 [consultado el 30 de agosto de 2019]).

44 Santos Sánchez 1993, 63; su transcripción se recogió en HEp 5, 1995, 253, a partir de la foto. Esteban Ortega $2019,84, n^{\circ} 1416$, reproduce la misma foto y quasi verbatim, lo dicho por Santos, lo que facilita el conocimiento de una publicación que se difundió tan poco que no se encuentra en ninguna biblioteca universitaria española: solo hay ejemplares en las bibliotecas públicas de Badajoz, Cáceres y Toledo y de algunos pueblos de esas tres provincias. 


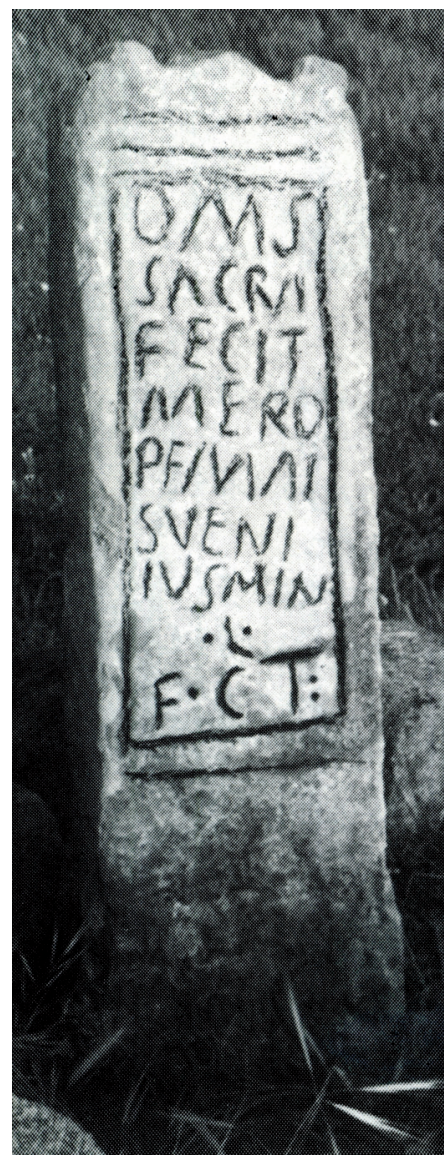

Fig. 13. Epitafio de Merope (C) M. Santos 1993).

Sin embargo, examinada de nuevo la pieza, la lectura resulta clara (Fig. 14):

$D($ is $) \cdot M($ anibus $) \cdot s($ acrum $) /$ Sacra $\beta$ fecit / Mero/pe mat(ri) /o sue ânn(orum) / L V Chedera $\mathrm{H}$ Hin $(---) / \cdot l($ iberta, $-u s) \cdot \rho f($ aciendum) $\cdot c($ uravit) (ex) t(estamento) $\cdot$

6: NI, Sánchez et alii, pero la segunda letra es con seguridad una N, por lo que la primera puede el nexo AN.

7: IVSMIN, Sánchez et alii. La V es segura, precedida por un astil; aunque lo que parecen mostrar las fotos es la doble panza de una B, es una L. Lo que anteriores editores transcribieron como SM es una hedera, ya que su forma es más lanceolada que circular y se distinguen el pezón y el ápice de la hoja; el rasgo siguiente es confuso, pero probablemente se trata de una $\mathrm{H}$ seguida de IN.

Aunque no consta en los repertorios onomásticos habituales ${ }^{45}$ Sacra fue un antropónimo femenino, no muy corriente pero sí bien documentado, i.e. Sacra

45 Aunque sí la forma masculina Sacrus y sus derivados, porque la raíz sacro- fue muy productiva en la onomástica céltica (Delamarre 2003, 264-265) y latina (Kajanto 1965, 211). 
Sauronis $f$. o Sacra filia eius. ${ }^{46}$ La dispersión del nombre corresponde a las áreas célticas del Imperio (Cisalpina, Galias, Germanias) y este epígrafe atestigua por primera vez su uso en las provincias hispanas.

A pesar de que tampoco fue muy popular, las dos formas del otro antropónimo estaban ya acreditadas en Hispania, en el carmen sepulchrale de Fabia Merope y en el epitafio de dos siervos de C. Iulius Merops: en el primer caso, la condición libertina de la difunta es explícita y es de suponer que lo mismo sucede también con el dedicante de la otra inscripción. ${ }^{47}$

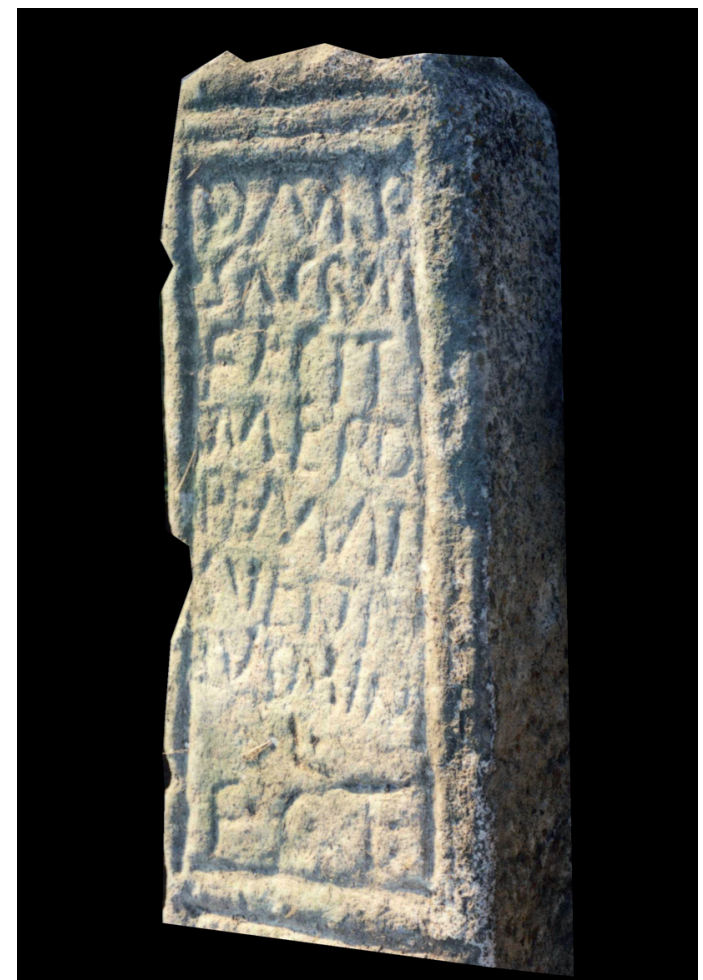

Fig. 14. Epitafio de Merope ( A. Gónzález Cordero 2012).

Como la última letra de la quinta línea es claramente una T, la lectura mat(ri) sue es segura. A partir de ahí, la erosionada superficie del monumento causa incertidumbre, pero lo que queda no es incompatible con la mención de la edad repartida entre las dos letras finales de lín. 6 y las iniciales del siguiente renglón. La hedera separa los datos del difunto de la cláusula dedicatoria del epitafio. No fueron muchos,

46 Respectivamente CIL III 5351, de Flavia Solva, y AE 2005, 1127, de Mogontiacum. Otros testimonios son AE 1955, 230, de Losheim; CLE 1436, de Mediolanum; CIL XIII 356, de Lugdunum Convenarum; CIL XIII 830, de Burdigala (Sacrina); CIL XIII 4646, de Leuci; y CIL XIII 5743, de Andematunum. La lista podría ser más amplia, pero hay epígrafes votivos en los que el significado de sacra es ambiguo, como sucede en CIL IX 5350.

47 Respectivamente Chic García 1975, 359-361, de Peñaflor, en la Bética, y CIL II²/14, 1578, de Tarraco; la práctica romana de usar nombres griegos para los esclavos era una muy plausible hipótesis que ahora está refrendada por varios estudios cuantitativos y que, por lo tanto, se considera un indicio fiable de la condición libertina, vid. Mouritsen 2012, 124-126, con amplia bibliografía. 
ni populares, los nombres personales que comienzan con Hin(- - -); Kajanto lista Hinnicius, Hinnus e Hinnulus, pero del primero no hemos encontrado su fuente; del segundo existen variantes para los dos géneros, con la nasal doble o simplificada y los diminutivos masculinos, de los cuales Hinnulus refiere a un mismo individuo que aparece en los programmata pompeyanos, en uno de ellos con el nombre abreviado; y hay que añadir Hinad, Hinitus e Hinierus. ${ }^{48}$

Ex t(estamento) f(aciendum) c(uravit) figura en un epitafio aparecido en las proximidades de Olisipo y en otros lugares del Imperio. Y aunque el orden habitual de la fórmula es el indicado, una inscripción de Vasio ofrece la secuencia f(aciendum) c(uravit) ex testamento, lo que lleva a suponer que la caída de la preposición en el monumento de Augustobriga se debió a la rusticidad del formulario o a la falta de espacio en el último renglón. ${ }^{49}$

La invocatio y el uso de nomina simplicia apuntan a una fecha tardía, del s. III d.C. en adelante.

\section{b) Estela con busto}

En la misma escombrera donde está la pieza anterior, apareció también una estela mutilada por abajo y a la que falta parte de la cabecera, seguramente redondeada, con pérdida de la hornacina y del busto por el costado derecho. Mide (87) x 42 x 23 $\mathrm{cm}$. Bajo la escultura, separado por un motivo muy erosionado que únicamente se aprecia en el lado izquierdo (¿un delfín?), sigue la inscripción en el fuste rebajado. Solo se distinguen, pero de forma incierta, un par de letras, que parecen capitales de buena factura. Las dimensiones del monumento y de las letras no se registraron. Descrito y fotografiado al mismo tiempo que el anterior y, como él, posiblemente sigue en el mismo lugar (Fig. 15).

$$
[---]+[---/--] S S O[---]
$$

La primera cruz corresponde a un rasgo vertical que no permite identificar la letra. En la segunda línea, el primer carácter apenas se distingue.

González Cordero 2001, considerándola anepígrafa y de él, Esteban Ortega 2019.

\section{A modo de conclusión.}

Dado el estado de conservación y el contenido de la docena de inscripciones catalogadas, difícilmente puede señalarse otro rasgo común que su vulgaridad, porque son los típicos documentos que pueden encontrarse en cualquier oppidum del interior de Hispania. Lo que las hace extraordinarias es que, a pesar de su escaso

48 Kajanto 1965, 327. Hinus, -a / Hinnus, -a: CIL VIII 202 (=ILT 320), El Garra; AE 1969/70, 731, Tipasa, de época cristiana; CIL III 12014.622, Virunum, marca de alfar; y Gregori 2001, $\mathrm{n}^{\mathrm{o}}$ 55. Hinill[- - -]: CIL III 10183.57, Dalmatia, estampilla del alfarero; Hinnullus: CIL IV 7373, 7374, 9851, Pompei; Hinad: ILRRP 295: Hinitus CIL VIII 22790, Silesua; Bull. Arch. Comm. Trav. Hist 1899, 550, Capsa; y el alfarero Sex. Vimiatius Hinierus, cuyas estampillas constan en Placentia (CIL XV 1517.07) y en Roma (CIL XV 1517.1-6 y 8-11).

49 CIL II 321, Torres Vedras; también CIL XIII 8843 e IAMSuppl. 508, Volubilis; Gascou - Guyon 2005, nº 79, Vasio. La fórmula sin preposición en CIL II 5229, también de Torres Vedras. 
valor documental, estudiarlas deja el placentero sabor de boca de haber podido demostrar que la curiosidad y la paciente labor de prospección aún pueden rescatar lo que se daba por inexorablemente perdido tras medio siglo de encontrarse bajo las aguas del Tajo.

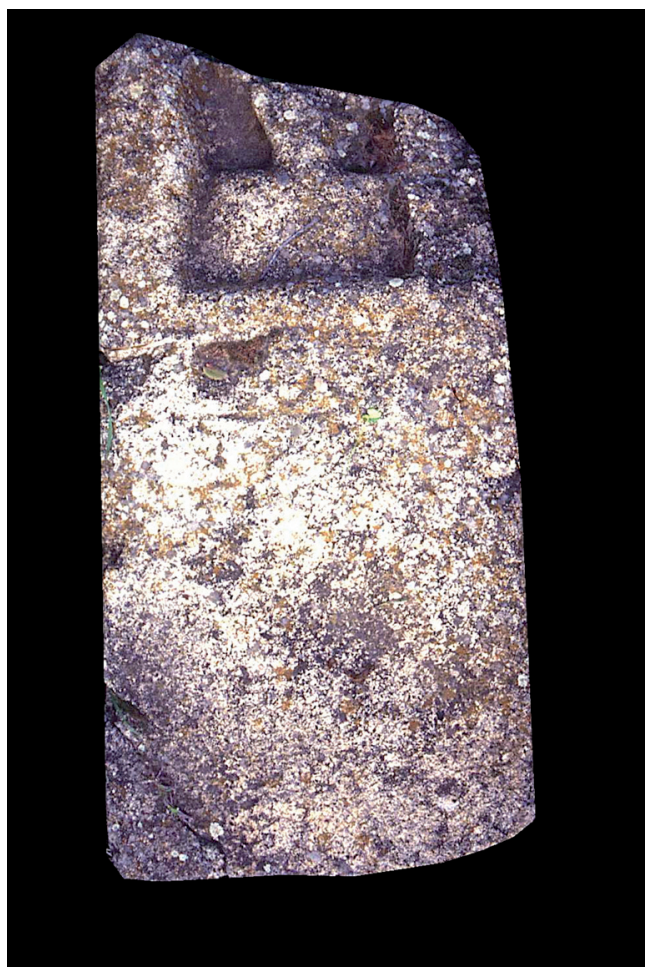

Fig. 15. Estela con busto (C A. Gónzález Cordero 2012).

\section{Referencias bibliográficas}

Abascal Palazón, J. M. (2013): “Cuestiones epigráficas del conventus Cathaginiensis, con algunas consideraciones póstumas de Géza Alföldy", [en] J. López Vilar (ed.), Tarraco Biennal. Actes. 1er Congrés Internacional d'Arqueologia i Món Antic. Govern i Societat a la Hispània Romana. Novetats epigràfiques. Homenatge a Géza Alföldy, Tarragona, 13-34. Beltrán Ortega, A. (2016): Epigrafía y territorio: Las civitates de la Asturia Meridional y la Lusitania Nororiental, Tesis doctoral, Universidad Complutense de Madrid.

Camprubí, L. (2014): Engineers and the Making of the Francoist Regime, Cambridge, MA.

Caron, L. (1996): “Art et société d'après les stèles funéraires de Cárquere”, Conimbriga 35, 69-106.

Chic García, G. (1975): “Inscripciones de Peñaflor”, Habis 6, 357-364.

Cornide Saavedra, J. (1796): "Continuación de la Memoria de Ignacio de Hermosilla sobre las ruinas de Talavera la Vieja", Memorias de la Real Academia de la Historia 1, 363-408.

Degrassi, A. (1957 y 1963): Inscriptiones latinae liberae Rei publicae, Göttingen-Firenze $(=I L L R P)$.

Delamarre, X. (2003): Dictionnaire de la langue gauloise: une approche linguistique du vieux-celtique continental, Paris. 
Díaz Andreu, M. - Ramírez Sánchez, M. E. (2001): “La Comisaría general de excavaciones arqueológicas (1939-1955). La administración del patrimonio arqueológico en España durante la primera etapa de la dictadura franquista", Complutum 12, 325-341.

Esteban Ortega, J.

(2012): Corpus de inscripciones latinas de Cáceres, vol. 2: Turgalium, Cáceres.

(2019): Corpus de inscripciones latinas de Cáceres, vol. 5: Augustobriga, Cáceres.

Forner y Segarra, A. F. (2017): Apuntamientos para las antigüedades de Extremadura, Cáceres (transcripción, edición y notas de E. Cerrillo Martín de Cáceres).

García y Bellido, A. (1956-1961): "Excavaciones en Augustobriga”, Noticiario Arqueológico Hispánico 5, 235-237.

Gascou, J. - Guyon, J. (2005): La collection d'inscriptions gallo-grecques et latines du musée Calvet, Paris.

Gimeno Pascual, H. (2016): “Aportaciones a la epigrafía de Augustobriga (Talavera La Vieja, Cáceres)", [en] E. Redondo-Moyano - M. J. García Soler (eds.), Nuevas interpretaciones del Mundo Antiguo. Papers in Honor of Professor José Luis Melena on the Occasion of his Retirement (=Anejos de Veleia, Series Minor 33), Vitoria-Gasteiz, 155-171.

Gómez de Castro, A. (1572): "Carta en donde cuenta del viaje que hizo a Jaraicejo a ver al obispo de Plasencia D. Pedro de Ponce de León, dando razón de algunas antigüedades que advirtió particularmente en Talavera la Vieja y Talavera de la Reina, con noticias de Jaraicejo, Rocafrida, Oropesa y Talavera de la Reina”, Biblioteca Nacional de España, Ms. 13009, ff. 96-101.

Gómez-Pantoja, J. L.

(2011): "Un nuevo terminus Augustalis en Lusitania", [en] A. Sartori - A. Valvo (eds.), Identità e Autonomie nel mondo romano occidentale (Iberia-Italia Italia-Iberia. III Covegno Internazionale di Epigrafia e Storia Antica, Gargnano, 12-15 maggio 2010), Faenza, 291-317.

(2019): "El dilema de Paramio", Cuadernos de Arqueología de la Universidad de Navarra 28, 157-166 (http://dx.doi.org/10.15581/012.28.007).

González Cordero, A.

(1999): "El Puente del Conde (Berrocalejo-Peraleda de San Román)”, [en] IV Coloquios Histórico-culturales del Campo Arañuelo, dedicados a León Moyano, Navalmoral de la Mata, 9-30.

(2001): "Catálogo de las inscripciones romanas del Campo Arañuelo, La Jara y Los Ibores”, [en] D. Quijada González (ed.), VII Coloquios Histórico-culturales del Campo Arañuelo - Don Justo Corchón García (Navalmoral de la Mata, 20 al 24 de noviembre de 2000), Navalmoral de la Mata, 115-164.

González Cordero, A. - Morán Sánchez, C. (2006): “Talavera la Vieja y su entorno arqueológico", [en] F. J. Jiménez Ávila (ed.), El conjunto orientalizante de Talavera la Vieja (Cáceres), (=Memorias 5), Cáceres, 19-43.

González Germain, G.

(2011): Estudi $i$ edició de les inscripcions llatines falses d'Hispania (ca. 1440-1550), Tesis doctoral, Universidad Autónoma de Barcelona.

(2015): "E scholio in lapidem. Recreaciones humanísticas epigráficas de un pasaje de Juvenal (sch. 6,638)", [en] J. M. Maestre Maestre et alii (eds.), Humanismo y pervivencia del mundo clásico. V: homenaje al profesor Juan Gil, Alcañiz-Madrid, vol. I, 511-521.

Gorrochategui, J. - Fernández Corral, M. (2016): “Cinco nuevas estelas funerarias procedentes de Belorado (Burgos)", Zeitschrift für Papyrologie und Epigraphik 197, 276-282.

Gregori, G. L. (2001): La collezione epigrafica dell'Antiquarium comunale del Celio: 
inventario generale, inediti, revisioni, contributi al riordino (=Tituli 8), Roma.

Hermosilla y de Sandoval y Rojas, I. (1796): "Noticia de las ruínas de Talavera la Vieja", Memorias de la Real Academia de la Historia 1, 345-362.

Hernando Sobrino, $\mathrm{M}^{\mathrm{a}}$ del $\mathrm{R}$.

(2002): "Cuando la fama te precede: Jerónimo Román de la Higuera y la epigrafía hispana", [en] Á. Alonso Ávila - S. Crespo Ortiz de Zárate (eds.), Scripta antiqua in honorem Ángel Montenegro Duque et José María Blázquez Martínez, Valladolid, 501-515.

(2005): Epigrafía romana de Ávila (=PETRAE Hispaniarum 3), Bordeaux-Madrid.

(2009): Manuscritos de contenido epigráfico de la Biblioteca Nacional de Madrid (siglos XVI-XX). La transmisión de las inscripciones de la Hispania romana y visigoda, Madrid.

Higuera, J. R. de la (s. XVI): Historia eclesiástica de España, vol. V, Biblioteca Nacional de España, Ms. 1642.

Hübner, E. (1869): Corpus inscriptionum latinarum. vol.2, Inscriptionum Hispaniae latinae, Berlin (=CIL II).

Hurtado de San Antonio, R. (1977): Corpus provincial de inscripciones latinas: Cáceres, Cáceres.

Jiménez de Gregorio, F. (1955): "Hallazgos arqueológicos en La Jara (VII)”, Archivo Español de Arqueología 91, 179-187.

Kajanto, I. (1965): The Latin Cognomina, Helsinki.

Labory, N. et alii (2003): Inscriptions antiques du Maroc. Supplément, Paris (=IAMSuppl.)

Machimbarrena Gogorza, V. (1926): "Puentes sobre el río Tajo (III). Provincia de Cáceres. Puentes del Cardenal, Almaraz, Alarza y Conde", Revista de Obras Públicas 74/2467, 521-524.

Medrano, J. M. (1997): "Ignacio de Hermosilla y la inspección ocular de las ruinas de Talavera la Vieja”, [en] Anticuaria y arqueología: imágenes de la España antigua, 17571877, Madrid, 29-32.

Mélida y Alinari, J. R. (1919): "Monumentos romanos de la antigua Augustóbriga, hoy Talavera la Vieja, en la provincia de Cáceres", Boletín de la Real Academia de la Historia $75,415-426$.

Merlin, A. (1944): Inscriptions latines de la Tunisie, Paris (=ILT).

Morán Sánchez, C.

(1996): "Augustobriga. Resurgimiento en la historiografía de los siglos XVIII y XIX", [en] D. Quijada González (ed.), II Coloquios Histórico-Culturales del Campo Arañuelo. Dedicados a D. Antonio $M^{a}$ Concha y Cano, Navalmoral de la Mata, 21-48.

(2017): "La documentación inédita de las excavaciones de A. García y Bellido en Augustobriga", [en] M. Ayarzagüena Sanz - G. Mora - J. Salas Álvarez (eds.), 150 años de Historia de la Arqueología: teoría y método de una disciplina (IV Congreso Internacional de Historia de la Arqueología, Madrid 11-13-Nov-2014), (=Memorias de la Sociedad Española de Historia de la Arqueología III), Madrid, 357-376.

Mouritsen, H. (2012): The Freedman in the Roman World, Cambridge (https://doi. org/10.1017/CBO9780511975639).

Quijada González, D. (1999): Talaverilla (=Pueblos en blanco y negro 12), Navalmoral de la Mata.

Redentor, A. (2002): Epigrafia romana na região de Bragança (=Trabalhos de arqueologia 24), Lisboa.

Salas Martín, J. (1985): "Notas acerca de la Augustobriga vettona (actual Talavera la Vieja)", Norba 6, 51-66.

Sánchez Cantón, F. J. (1927): "Viaje de un humanista español a las ruinas de Talavera la 
Vieja", Archivo Español de Arte y Arqueología 8/13, 221-227.

Sánchez Medina, E. (2004): "El maestro Alvar Gómez de Castro y la epigrafía", [en] J. M. Maestre Maestre et alii (eds.), Humanismo y pervivencia del mundo clásico. Homenaje a Antonio Fontán, Madrid, vol. 1, 437-446.

Santos Sánchez, M. (1993): Historia de Talavera la Vieja (la antigua Augustobriga), Talavera de la Reina. 